Estudios Constitucionales, Año 9, No 1, 2011, pp. 157 - 198.

ISSN 0718-0195

Centro de Estudios Constitucionales de Chile Universidad de Talca

"La igualdad como redistribución y como reconocimiento: derechos de los

pueblos indígenas y Corte Interamericana de Derecho Humanos"

Laura Clérico - Martín Aldao

\title{
LA IGUALDAD COMO REDISTRIBUCIÓN Y COMO RECONOCIMIENTO: DERECHOS DE LOS PUEBLOS INDÍGENAS Y CORTE INTERAMERICANA DE DERECHOS HUMANOS
}

\section{EQUALITY AS REDISTRIBUTION AND RECONIGNITION: INDIGENOUS PEOPLES RigHTS AND THE INTER-AMERICAN COURT OF HumAN RightS}

\section{Laura Clérico*}

Profesora de Derecho Constitucional en la Universidad de Buenos Aires lauraclerico@yahoo.com

Martín Aldao**

Investigador adscripto del Instituto Gioja, Facultad de Derecho-UBA maldao@derecho.uba.ar

RESUMEN: Este trabajo se detiene en las fórmulas y concepciones de la igualdad que se juegan en el contexto interamericano. Se revisan criticamente las fórmulas de igualdad corrientes identificando la insuficiencia del análisis de los problemas de igualdad bajo el prisma del principio antidiscriminatorio, en tanto puede funcionar ante discriminaciones puntuales pero no logra dar cuenta de la desigualdad que responde a una desigualdad sistemática y estructural. Luego la inclusión de la perspectiva de igualdad como no-dominación o no-sometimiento es interpelada por las causas que generan esa desigualdad. Así proponemos ampliar la mirada para comprender que la desigualdad no sólo deviene de una distribución injusta de los bienes económicos y sociales sino también del reconocimiento. Esta última ampliación de las miradas sobre la desigualdad nos permite analizar con detenimiento los nuevos casos llegados a la Corte Interamericana de Derechos Humanos sobre pueblos originarios. En este trabajo sostenemos que la insuficiencia de estudios sobre igualdad en el contexto interamericano no sólo habla de una miopía que no permite ver que varios de los planteos de igualdad responden a una desigualdad como dominación o sometimiento, sino que también responde a una desigualdad que combina problemas de redistribución y reconocimiento como en el caso de los planteos de los pueblos originarios. Así, ser reconocido como un igual no sólo amplía nuestra mirada sobre los derechos, sino que devela la intima relación entre derechos, democracia deliberativa e igualdad, entendidas todas como lucha por la paridad participativa de los grupos desaventajados en el sistema interamericano. Todo esto servirá para re-interpretar las argumen-

\footnotetext{
"Doctora en Derecho por la Universidad de Kiel. Investigadora del CONICET. Artículo recibido el 23 de marzo de 2011.

" Doctor en Derecho por la Universidad de Buenos Aires. Becario posdoctoral CONICET 20112013.
} 
taciones de la Corte IDH en los casos relativamente recientes sobre pueblos originarios. El trabajo de estos casos nos permitirá a su vez poner a prueba nuestra propuesta.

ABSTRACT: As widely accepted as it is, the equality principle may be understood in, at least, three different ways. This paper, focused on the Inter-American context, examines firstly the problems of the standard conception of equality-i.e. as anti-discrimination-, showing that although it may solve specific problems, it cannot deal with the structural inequalities widely spread in Latin America. Secondly, we analyze the more ample scope offered by the conception of equality as antisubordination, in order to understand the deeply rooted causes of inequality in our social orders. Being these indentified, we add the more complex theoretical framework developed by $N$. Fraser, which accounts for both, redistribution and recognition issues when approaching inequalities. The wider scope on inequality provided by this theoretical framework improves not only our understanding of rights, but also expose the intimate connection between rights, deliberative democracy and equality, all three of them understood as the struggle for participatory parity of disadvantaged groups. As we believe it allows a better understanding of recent Inter-American Court of Human Rights decisions on indigenous peoples related cases, the last section of this paper is devoted to reinterpret these in order to test our thesis.

PALABRAS CLAVE: Igualdad-Redistribución-Reconocimiento-Pueblos Indigenas

KEYWORDS: Equality-Redistribution-Recognition-Indigenous People

\section{INTRODUCCIÓN Y PLANTEO DEL PROBLEMA}

En el contexto de prácticas constitucionales y de derechos humanos que reconocen como principios estructurantes el de autonomía e igualdad, es muy difícil dar una discusión seria sobre un problema en el que se excluye a algunos de algo que se les otorga a otros sin recurrir a un examen de igualdad. Sin embargo, las diferencias en las respuestas giran en torno a: la fórmula, la concepción ${ }^{1} y$ alcance de la exigencia igualdad aplicada. ${ }^{2}$

Justamente este trabajo se detiene en las fórmulas y concepciones de la igualdad que se juegan en el contexto interamericano cuando se trata de los reclamos de los pueblos o comunidades indígenas sobre acceso a sus tierras ancestrales ante la Corte Interamericana de Derechos Humanos (en adelante, Corte IDH). ${ }^{3}$ Tomamos tres reclamos de pueblos indígenas contra el Estado de Paraguay como "casos paradigmá-

\footnotetext{
${ }^{1}$ V. sobre diversas concepciones de la igualdad en aplicación de los desarrollos de Walzer para el análisis crítico de sentencias, MeCCIA (2010).

${ }^{2}$ V. CLÉrico (2010). El uso de diversas fórmulas de igualdad se puede seguir en el debate que se generó los días 14 y 15 de julio de 2010 en la Cámara de Senadores de la Nación Argentina en ocasión de la aprobación de la inclusión del matrimonio igualitario, que luego fuera promulgada como Ley 26.618, 2010 v. versión taquigráfica en: www.senado.gov.ar

${ }^{3}$ No se propone como un análisis integral de la jurisprudencia de la Corte IDH en materia de derechos indígenas, no obstante se abordará la problemática en la medida en que nos permitía retomar sentencias paradigmáticas en términos de aplicación del examen de igualdad, articulándolo con las nociones de redistribución y reconocimiento. S. análisis detallados de la jurisprudencia de la Corte IDH en la materia v., entre otros, CIDH (2011); Gialdino (2006), p. 1178; NASH Rojas (2003).
} 
ticos". Si bien estos tres casos son contra un Estado en particular, la negación de este derecho colectivo a los pueblos indígenas atraviesa todo el contexto interamericano más allá de algunas particularidades. ${ }^{4}$ Los casos de violaciones de este derecho contra los pueblos originarios ocurren también y por ejemplo en territorio argentino. En un informe reciente se diagnostica que 11.320.455 hectáreas son objeto de reivindicación por pueblos originarios, 680 mil integrantes de esos pueblos fueron desplazados y en varios casos de forma violenta, en donde los empresarios con interés en las tierras estarían actuando para desplazarlos con el apoyo de fuerzas de seguridad públicas y privadas, resultando varias personas heridas y hasta en algunos casos asesinadas. ${ }^{5}$ Los pueblos originarios son desplazados de sus tierras por móviles económicos, para explotar esas tierras (muchas de las veces implica, además, desforestación de bosques nativos) últimamente, por ejemplo, para cultivo de soja (por ejemplo, a través de los llamados "pools de siembra"); para explotación minera, de petróleo, etc... ${ }^{6}$.

De cara a este contexto, nuestro trabajo contiene una faz crítica, revisa las fórmulas de igualdad corrientes para detenerse en sus insuficiencias: así, criticaremos la insuficiencia del análisis de los problemas de igualdad bajo el prisma del principio antidiscriminatorio -ya sea interpretado como igualdad formal y/o material más (examen estricto) o menos exigente (mero análisis de racionalidad, escrutinio medio). Interpretamos que el principio antidiscriminatorio puede funcionar ante discriminaciones puntuales, pero no logra dar cuenta de la desigualdad que responde a una desigualdad sistemática y estructural: aquellas personas que padecen los efectos de esa discriminación no pueden salir de esa situación en forma individual y por sus propios medios (léase, personas con discapacidad, pueblos indígenas, niños y niñas, mujeres, ancianos, entre otras), sino que se requieren medidas de acción positiva, reparadoras o transformadoras para lograr igualdad real de oportunidades para el

${ }^{4}$ V. Ramírez (2008), p. 921.

${ }^{5}$ Ver los casos del 12/10/2009 en el que fue asesinado el líder indígena Javier Chocobar y el caso reciente, de noviembre de 2010, contra la comunidad quom con asiento en la Provincia de Formosa. El Centro de Estudios Legales y Sociales (CELS) y la Defensoría General de la Nación solicitaron a la CIDH una medida cautelar para garantizar la vida y la integridad física de los miembros de la comunidad toba quom La Primavera, en la provincia de Formosa, para el Estado argentino, a proteger a los indígenas y sus dirigentes, suspender todo acto de desalojo y promover la investigación y sanción de los responsables de los ataques. Por su parte, el 18/2/2011 la CIDH solicitó al Estado argentino que informe sobre las medidas que adoptó para proteger a los integrantes de la comunidad del pueblo toba, en Formosa, que sufrieron una feroz represión policial el 23 de noviembre pasado y que continúan siendo hostigados y amenazados por las fuerzas de seguridad provincial. Fuente: www.cels.org.ar

${ }^{6} \mathrm{~V}$. relevamiento sobre los desplazados de las tierras, en Tiempo Argentino, 14/11/2010: "En Salta desalojan a los pueblos originarios para buscar petróleo"; Clarín, 18/2/2009, "Los indígenas llegan a la Corte por los desmontes"; Tiempo Argentino, 7/3/2011, "Ya son diez los niños muertos por desnutrición en Salta este año", entre muchos otros. 
ejercicio de los derechos; es decir, consideramos pertinente ampliar la fórmula de igualdad como principio de no-dominación o no-sometimiento.7 Sin embargo, la inclusión de la perspectiva de igualdad como no-dominación o no-sometimiento quedaría a mitad de camino si no nos preguntáramos por las causas que generan esa desigualdad. Es decir, proponemos ampliar la mirada para comprender que la desigualdad no sólo deviene de una distribución injusta de los bienes económicos y sociales $^{8}$ sino también del reconocimiento9 (Fraser). Recién con esta última ampliación de las miradas sobre la desigualdad estaríamos en condiciones de analizar con detenimiento los nuevos casos llegados a la Corte IDH sobre pueblos indígenas. ${ }^{10}$

Nuestra tesis dice: la insuficiencia de estudios sobre igualdad en el contexto interamericano no sólo habla de una miopía que no permite ver que varios de los planteos de igualdad responden a una desigualdad como dominación o sometimiento, sino que también responde a una desigualdad que combina problemas de redistribución y reconocimiento como en el caso de los planteos de los pueblos originarios. Así, ser reconocido como un igual no sólo amplía nuestra mirada sobre los derechos, sino que devela la íntima relación entre derechos, democracia deliberativa e igualdad, entendidas todas como lucha por la paridad participativa ${ }^{11}$ de los grupos desaventajados en el sistema interamericano.

El desarrollo de nuestra tesis nos llevará primero a repasar las fórmulas de igualdad insuficientes (formal, material, como principio antidiscriminatorio en

\footnotetext{
${ }^{7}$ V. SABA (2007).

${ }^{8}$ La injusticia socioeconómica arraigada en la estructura político-económica de la sociedad respecto de la distribución de bienes (ejemplos de este tipo de injusticia se pueden vislumbrar en la explotación laboral, la marginación económica, la privación de los bienes materiales indispensables para llevar una vida digna, entre otros).
}

${ }^{9}$ La otra deviene de la injusticia cultural o simbólica, arraigada en los patrones sociales dominantes en una sociedad desde los que se interpreta con pretensión de "uniformidad", por ejemplo, cuál es la forma de matrimonio que debe ser reconocida sin que la voz concreta de quienes tienen una orientación sexual diferente y diversa sea escuchada en el proceso de decisión (así, ejemplos de este tipo de injusticia son la dominación cultural, el no reconocimiento y el irrespeto e incluye la discriminación a lesbianas, gays, travestis, personas trans, bisexuales, entre otros). Aplicamos ya la propuesta de Fraser de igualdad como redistribución y reconocimiento para analizar los reclamos de los pueblos originarios en SCHUjMAN et al. (2007); ClériCo (2008); v. además, CONTESSE (2010).

${ }^{10}$ En el presente trabajo se hablará indistintamente de "pueblos originarios", "pueblos indígenas" o "comunidades indígenas", sobre las posibles diferencias, v. STAVEnHAGEN (2010).

11 “... ser reconocido de forma errónea es... ser representado por unos patrones institucionalizados de valor cultural de un modo que impide la participación como igual en la vida social...”. Para que la paridad participativa pueda darse tienen que cumplirse dos condiciones: una condición objetiva y otra intersubjetiva. La condición objetiva dice que la "distribución de recursos materiales debe hacerse de manera que garantice la independencia y la 'voz' de todos los participantes". La condición intersubjetiva requiere que "los patrones institucionalizados de valor cultural expresen el mismo respeto a todos los participantes y garanticen la igualdad de oportunidades para conseguir la estima social". FrASER (2006), pp. 36, 42 y 45. 
sus tres formas de escrutinio, que arranca con uno leve pasa, por uno intermedio, para culminar en uno de tipo estricto), para ampliarla luego a la igualdad como no-dominación (II) e integrarla con la mirada de la redistribución-reconocimiento (III). Todo esto servirá para re-interpretar las argumentaciones de la Corte IDH en los casos relativamente recientes sobre pueblos originarios (IV). El trabajo de estos casos nos permitirá poner a prueba nuestra propuesta $(\mathrm{V})$.

\section{II. ¿¿IGUALDAD COMO MERO PRINCIPIO ANTI-DISCRIMINATORIO? CATEGORÍAS SOSPECHOSAS. INSUFICIENCIA DEL MODELO PARA ANALIZAR LOS NUEVOS CASOS DE IGUALDAD}

Todas las fórmulas de igualdad encierran en más o menos algún tipo de comparación entre dos personas, grupos de personas, situaciones, etc. La comparación surge del reclamo de trato igualitario y en dos sentidos:

(a) alguien que es tratado en forma diferente que otro quiere ser tratado de la misma manera porque considera que no hay razones para ser tratado en forma diferente; o bien (b) alguien que es tratado como otros considera que debe ser tratado en forma diferente porque hay una circunstancia relevante que justifica un trato diferenciado.

Para examinar si el reclamo debe prosperar se requiere examinar cuáles razones hablan a favor o en contra del planteo igualitario. Justamente la evaluación de estas razones (o sinrazones) es el centro del examen de igualdad y el resultado dependerá de la fórmula y concepción de la igualdad que se aplique.

Una de las formas de igualdad menos exigente es la fórmula de la igualdad formal. Esta fórmula dice que no se viola el mandato de igualdad en tanto aquellos que pertenecen a la categoría surgida luego de la clasificación realizada por el legislador son tratados de igual forma (se les aplique las mismas consecuencias jurídicas). Esta fórmula dice:

si la categoría alcanza a todas las $x$, entonces sólo se viola si una $x$ no es tratada como una de las $x$ de la categoría.

Es decir, no examina si el criterio y las razones por las que se realizó la clasificación son legítimas y si la clasificación tiene justificación alguna; tampoco nos dice algo "acerca de cómo deben ser tratados qué individuos con qué propiedades". ${ }^{12}$ Esta fórmula se encuentra detrás de la criticada -y con razón- fórmula de "separados pero iguales". Bajo esta fórmula se sostuvieron las leyes racistas en los Estados Unidos de Norteamérica. ${ }^{13}$ Bajo esta misma fórmula hubiese sido im-

${ }^{12}$ V. AleXY (2007), p. 351

${ }^{13}$ V. U.S.S.C. 163 U.S. 537 (1896). 
posible dictar el fallo "Brown vs. Board of Education", ${ }^{14}$ en el que se decidió que la separación por "raza" en las escuelas públicas violaba el mandato de igualdad. Por ello, resulta cuestionable que alguien utilice en la actualidad esta fórmula de igualdad para sostener la discriminación cuando alguien realiza un planteo serio de no-discriminación arbitraria. ${ }^{15}$

Por contraposición, una de las fórmulas de la igualdad que se pregunta por la legitimidad del criterio de clasificación y las razones de la selección, es la fórmula de la igualdad jurídica material. Esta fórmula dice que no se viola el mandato de igualdad si:

a todos los que se encuentran en igualdad de circunstancias relevantes se los trata de igual forma.

Es decir, si no hay ninguna razón suficiente para permitir un trato desigual, entonces está ordenado un trato igual. ${ }^{16}$ Por ejemplo, en el caso de la inclusión del matrimonio igualitario la pregunta es ¿̨por qué se les niega algo a las parejas del mismo sexo si están en igualdad de circunstancias relevantes que las parejas de distinto sexo? Tomamos por relevantes la voluntad de tener pareja, de gozar de las protecciones y derechos que surgen de la regulación legal del matrimonio. ${ }^{17}$ Por ello, quienes siguen estando en contra de la inclusión del matrimonio igualitario tienen el desafío argumentativo de justificar por qué no estarían en igualdad de circunstancias relevantes. ${ }^{18}$ En suma,

\footnotetext{
${ }^{14}$ U.S.S.C. 347 U.S. 483 (1954).

${ }^{15}$ V. esta misma advertencia en el caso "Freyre Alejandro y otro c/ GCBA s/ Amparo (expte. N 34292/0)", Juzgado No15, Fuero CAyT, en el que se declaró la inconstitucionalidad del Art. 172 del Código civil argentino antes de la reforma de 2010 que no admitía el matrimonio igualitario.
}

${ }^{16}$ V. AlEXy (2007), p. 360.

${ }^{17}$ Incluso el Tribunal Europeo de Derechos Humanos en su sentencia del 24/06/2010, "Schalk y Kopf vs. Austria", parte en forma correcta del presupuesto de que los actores, pareja de personas del mismo sexo, "estaban en una situación similar a las parejas de distinto sexo". Sin embargo, el Tribunal en su posición mayoritaria concluye que no hubo discriminación por parte del Estado austríaco que no reconoce el matrimonio igualitario. En este punto, es más convincente el voto en disidencia de los jueces Rozakis, Spielmann y Jebens, quienes critican a la posición mayoritaria en tanto el Gobierno austríaco no esgrimió argumento alguno para la diferencia de trato, fundándose tan sólo en su margen de apreciación. Y agregan que en tanto no dieron argumento no sería posible escudarse en este margen, "de hecho, sólo en caso de que las autoridades nacionales ofrezcan fundamentos de justificación, la Corte puede interpretar, teniendo en cuenta la presencia o la ausencia de un enfoque común [entre las legislaciones de los estados partes], que están mejor ubicados que ella para tratar eficazmente la cuestión”, párr. 8. Queda claro que el margen de apreciación de los Estados no es una razón de peso suficiente para justificar una diferencia de trato ni menos aún para ser la primera y única ratio. Cursiva agregada. Para un análisis detallado y crítico de la sentencia, v. Kemelmajer de Carlucci y Herrera (2010).

${ }^{18}$ V. Gargarella (2010) y Clérico (2010). 
y como reitera la Corte IDH, es discriminatoria una distinción que carezca de justificación objetiva y razonable ${ }^{19}$.

Ahora bien, la fórmula de igualdad material implica el desarrollo de tres subexámenes para determinar si existen razones suficientes o no para un trato desigualitario. Esos tres subexámenes son los de idoneidad, medios alternativos menos lesivos y proporcionalidad en sentido estricto. La aplicación de la proporcionalidad en el examen de igualdad ayuda para determinar si el criterio de distinción que genera las categorías o grupos (medida estatal) tiene relación con las finalidades (razones) de la norma. ${ }^{20} \mathrm{El}$ subexamen de idoneidad se pregunta si el medio logra promover los fines estatales y si no lo logra entonces ya tenemos una primera razón que habla en contra del trato desigualitario. El subexamen de medios alternativos dice que las razones de la distinción no son suficientes si pudo haberse evitado el trato desigualitario a través de la implementación de algún otro medio alternativo (es decir, uno que evite esa clasificación). El subexamen de proporcionalidad en sentido estricto supone determinar la intensidad de restricción a la igualdad y a los derechos que produce la clasificación y, por el otro lado, determinar el peso de las razones que hablan a favor de la clasificación y de la promoción del fin estatal. Por ello, no hay razones suficientes para la distinción si la intensidad de restricción es mayor que el peso de las razones justificatorias.

Estos tres subexámenes ayudan para determinar si la distinción/discriminación es o no arbitraria. Ahora bien, estos tres subexámenes de igualdad pueden ser aplicados con mayor o menor intensidad, esto depende de qué tan exigentes nos pongamos para evaluar la relación entre la clasificación, el criterio de clasificación, sus efectos y las razones justificatorias. Por ello, se suele hablar de tres escrutinios de igualdad jurídica material: un escrutinio leve o de mera racionalidad, un escrutinio intermedio y un escrutinio bien exigente.

En el examen de igualdad de mera racionalidad se parte de la presunción de legitimidad/constitucionalidad de la clasificación realizada por el legislador. Esto significa que la carga de la argumentación la tiene quien realiza el reclamo igualitario y sólo se declarará la clasificación y sus efectos como arbitrarios si logra argumentar que no existe relación alguna entre medio y fin y que esa falta

${ }^{19}$ Cfr. Corte IDH, OC-18/03 (2003), párr. 89; OC-17/02 (2002), párr. 46; y OC-4/84 (1984), párr. 56. Esto genera diversas obligaciones a los Estados que tienen la obligación de no introducir en su ordenamiento jurídico regulaciones discriminatorias, eliminar las regulaciones de carácter discriminatorio, combatir las prácticas de este carácter y establecer normas y otras medidas que reconozcan y aseguren la efectiva igualdad ante la ley de todas las personas.

${ }^{20}$ V. Alexy (1986 y 2007); Clérico (2001 y 2009a); Bernal Pulido (2007). 
de relación justificatoria es evidente, manifiesta; de lo contrario, se confirma la presunción a favor de la legitimidad de la clasificación.

El escrutinio intermedio exige una relación más sustancial entre clasificación, criterio de clasificación, efectos de la clasificación y razones justificatorias, la relación tiene que ser plausible, demostrarse una relación estrecha entre clasificación y razones justificatorias y alegarse algún fin estatal importante que justifique la clasificación.

Sin embargo, el más exigente de los exámenes es el estricto. ${ }^{21}$ Esto implica:

(a) partir de la presunción de la arbitrariedad de la discriminación;

(b) la carga de la argumentación se traslada en cabeza de aquellos que alegan la justificación de la clasificación, por lo general, el Estado;

(c) una exigencia agravada de justificación, la arbitrariedad sólo puede ser revertida si quien tiene la carga de la argumentación logra alegar y justificar razones más que importantes, por ejemplo, un fin estatal imperioso más que urgente,

(d) que no existía ningún otro medio alternativo que pudiera evitar la clasificación;

(e) una regla epistémica, que dice que si persisten dudas al final de la argumentación, queda la clasificación y sus efectos como arbitraria. El examen de escrutinio estricto se aplica, por ejemplo, cuando desde el vamos del planteo de la cuestión igualitaria se "sospecha" que la exclusión huele a injustificada e inconstitucional porque afecta a un grupo de personas que históricamente ha sido discriminado y que las consecuencias perjudiciales para sus derechos persisten en la actualidad..$^{22}$ Nos encontramos frente a una exclusión sospechosa (por ejemplo, discriminación basada en la "raza", la etnia, la nacionalidad, la orientación sexual, etc.) y quien no crea que esas personas no conformen un grupo de personas histórica y sistemáticamente discriminadas tiene la carga de la argumentación y debe justificar por qué no lo son al ser excluidas de lo que se les otorga a otros en igualdad de circunstancias relevantes (FERNANDEZ VALLE, 2010).

Si bien este última intensidad de examen de igualdad jurídica material es mucho más exigente, nos preguntamos si es una herramienta argumentativa lo suficientemente potente para conmover un status quo fuertemente desigualitario. Es decir, un status quo en el que la discriminación no es sólo puntual o individual, sino que responde a una práctica sistemática de discriminación cuyos efectos no

\footnotetext{
${ }^{21}$ V. Garay (1989); Bianchi y Gullco (2001); Clérico y SChVARTZMan (2007); Treacy (2006); Gargarella (2007); Clérico (2007b); Maurino (2007), p. 330. Dulitzky (2007) reconstruye el examen de igualdad en el contexto interamericano como principio antidiscriminatorio e incluyendo "categorías sospechosas".

${ }^{22}$ Se aplica examen estricto de igualdad, en materia de discriminación por orientación sexual en: Contencioso Administrativo Tributario de la Ciudad Autónoma de Buenos Aires: "Freyre Alejandro y otro c/ GCBA s/ Amparo (expte. N 34292/0)"; "Canevaro Martín y otro c/ GCBA s/ Amparo (expte. N 36410/0)", Juzgado del Fuero No 13; "Fernández Alberto Daro y otro c/ GCBA s/ Amparo (expte. N 36320)", entre otros.
} 
pueden ser revertidos en forma individual por las personas afectadas por los efectos de esa discriminación. Pensemos, por ejemplo, en el contexto interamericano en la situación de exclusión que viven varios pueblos originarios por falta de acceso a la posesión a sus tierras ancestrales y que incluso implica la muerte de algunos de sus miembros cuando buscan defenderse frente a procesos de desalojo de sus tierras. ${ }^{23}$ Algunas de las constituciones incluso identifican a esos grupos desaventajados como mujeres, niños y niñas, ancianos, personas con discapacidad, pueblos originarios, entre otros (ver, por ejemplo, del Art. 75, incs. 23 y 17 de la Constitución argentina).$^{24}$ Esta desigualdad no es natural, sino que surge como producto de una estructuración social dada. Para que estos grupos vulnerables puedan ejercer sus derechos en condiciones de igualdad, se deben dictar medidas estatales de acción positiva. Este mandato implica un empezar a hacer positivo, con lo que la norma se viola si el legislador: i) sigue omitiendo, ii) retrocede arbitrariamente sobre lo hecho, o si iii) lo hecho por acción es insuficiente o defectuoso.

Así, esta exigencia de igualdad se presenta como una exigencia de no-dominación o no-sometimiento e implica una mirada crítica sobre la igualdad interpretada como mera igualdad formal o jurídico-material. Esta mirada crítica, a su vez, invita a volver la mirada sobre los presupuestos de filosofía política sobre los que se basa cada una de las concepciones de igualdad.

\section{IGUALDAD COMO REDISTRIBUCIÓN Y RECONOCIMIENTO}

Una interpretación meramente formal de la igualdad o incluso como igualdad jurídico-material tiene el defecto de esconder, tras el principio de igualdad ante la ley, una serie de desigualdades de orden material y simbólico que no se corres-

${ }^{23}$ Nos referimos, por ejemplo, a la muerte de integrantes del pueblo quom en la provincia de Formosa (Argentina) del 26/11/2010.

${ }^{24}$ Quien evalúa una acción u omisión estatal tiene que tener en cuenta que la afectada puede converger en más de uno de los grupos desaventajados del Art. 75 inc. 23 de la Constitución Nacional. Por ello, es necesario reconstruir la situación de la actora teniendo en cuenta el enfoque de la llamada "discriminación múltiple" o "discriminación interseccional". Así, se interpreta que la discriminación que surge de una combinación de elementos ocasiona un tipo de discriminación diferente de cualquier otra basada en un solo factor. La pertinencia de la aplicación de este tipo de enfoque está dada por la atención que presta a los contextos históricos, sociales y políticos que generan estas discriminaciones, esto permitiría, además, encontrar soluciones adecuadas a las experiencias particulares de las personas discriminadas. Por ejemplo, mujeres mayores con discapacidad pertenecientes a pueblos originarios pueden sufrir más discriminación que mujeres y varones con discapacidad que viven en zonas urbanas y cerca de centros de atención y rehabilitación. Véase el enfoque de la "discriminación interseccional" aplicado para analizar el derecho a la vivienda de mujeres en: Informe del Relator Especial sobre una vivienda adecuada como elemento integrante del derecho a un nivel de vida adecuado y sobre el derecho de no discriminación a este respecto, KOTHARI (2006), pár. 47-54. Este tipo de discriminación se examina en el caso Yake Axa, en donde la desigualdad se agudiza respecto de los niños, ancianos y mujeres de la comunidad indígena. 
ponden con los exigentes presupuestos normativos de la democracia, pero que a la vez, tampoco pueden ser resueltos dentro del estrecho marco de los derechos individuales.

Esto es así en tanto en la idealizada autocomprensión de las sociedades burguesas, que sirvieron de matriz al constitucionalismo liberal, la igualdad es concebida como un presupuesto y no como una meta. ${ }^{25}$ Esto tiene al menos dos consecuencias relevantes: en primer lugar, se asume que determinado status quo, cortado a la medida del hombre de negocios occidental, constituye una suerte de orden natural que determina el alcance de la discusión en materia de igualdad. ${ }^{26}$ En este sentido, la igualdad es reconstruida en términos de no intervención estatal sobre una sociedad civil que es capaz de regularse autónomamente. ${ }^{27}$ En segundo lugar, se atribuye al derecho y a la jurisprudencia un rol de preservación y restitución de este orden natural, restringiendo las discusiones políticas -aquellas que excedan la mera restauración del equilibro natural entre oferta y demanda por un lado, y derechos individuales (en su formulación clásica) por el otro- a un debate parlamentario que en realidad se desarrolla bajo la supervisión de aquellos que, sin quebrar esta peculiar comprensión del principio de igualdad ante la ley, han logrado ubicarse por encima de sus pares. De este modo, no sólo se cristalizan aquellas desigualdades invisibles a la matriz liberal-burguesa, sino que se aumenta la brecha entre unos y otros. ${ }^{28}$

Sin embargo, como apuntan Habermas (2005, cap. 7) y Sousa Santos (2009, caps. 7 y 9), el ideal normativo de la Ilustración, reconstruido en términos de objetivo, nos permite:

(a) plantear el problema de la igualdad en términos no ya de restauración sino de emancipación (de no-dominación o no-sometimiento),

(b) pensar la democracia no tanto como un hecho sino como un proyecto a realizar y

(c) establecer con mayor claridad la mutua implicación de ambas.

Es en este sentido que tomarse la democracia en serio requiere integrar el principio de igualdad, de modo tal que pueda dar efectiva cuenta del ideal de una sociedad de individuos libres e iguales. Es en orden a resolver las falencias del mode-

\footnotetext{
${ }^{25}$ ARENDT (2006), pp. 188 y ss.

${ }^{26}$ En este sentido, es relevante señalar que lo que habitualmente denominamos "igualdad formal-legal" no es pura forma en términos absolutos, sino sólo para aquellos que no encajan en el molde de la subjetividad liberal-burguesa; en otros términos, que aquellos que sí caben en ésta no pueden sino verla como llena de contenido. Sin embargo, y en tanto es mayor el número de excluidos que el de incluidos en este estrecho molde, decidimos mantener el uso habitual del término.
}

${ }^{27}$ Habermas (2004), pp. 112 y ss.

${ }^{28}$ Fraser (1997); Young (1989). 
lo liberal que se han ensayado diversas reconstrucciones del principio de igualdad, entre las que se destacan las nociones de redistribución y de reconocimiento.

La idea de igualdad como redistribución tiene sus orígenes teóricos en el intento de compatibilizar el ideal liberal de libertad individual con las demandas igualitaristas de la social democracia; y apunta a los déficits que en, términos de acceso a recursos materiales, fracturan a la sociedad en propietarios, asalariados y desposeídos. Desde esta perspectiva, la naturalización del estado de cosas vigentes y la obturación de los intereses de aquellos que no pertenecen a los grupos dominantes se traduce en legitimación de las desigualdades en términos de acceso a recursos materiales y aumento de la brecha entre ricos y pobres. De este modo, se produce un círculo vicioso en el cual las desigualdades de propiedad no pueden ser alteradas por el principio de igualdad formal, reforzando las dificultades de acceso de trabajadores y desposeídos a las instancias de participación política, que son a su vez las únicas que podrían modificar esta estrecha comprensión de la igualdad. Lo que define a esta particular perspectiva de la justicia social es su creencia en que la transformación de las relaciones de producción constituye el remedio fundamental para la solución de las desigualdades. En este sentido proponen la redistribución del ingreso o la riqueza, la redistribución de la división del trabajo y la reestructuración de la propiedad privada y de la empresa, entre otros. A su vez, identifican en la clase desposeída de recursos al principal grupo afectado; y a la eliminación de las diferencias materiales como la solución a la desigualdad, ${ }^{29}$ a lo que se suma el cuestionamiento, en sus versiones más radicales, de los criterios que se utilizan para definir el acceso a la producción.

Por su parte, la idea de igualdad como reconocimiento proviene de la filosofía continental, con más precisión de la fenomenología de la conciencia, y busca resolver el problema de la formación de la subjetividad apuntando a los déficits que, en términos de acceso a los recursos simbólicos, fracturan a la sociedad en subjetividades dominantes y dominadas. Desde esta perspectiva, la naturalización del estado de cosas vigentes y la obturación de los intereses de aquellos que no pertenecen a los grupos dominantes se traduce en la legitimación de las desigualdades de status dentro de la sociedad y el aumento de la brecha entre unos y otros. De este modo, también se produce un círculo vicioso, en el cual las desigualdades de reconocimiento no pueden ser alteradas por el principio de igualdad formal ni tampoco por el de igualdad material, reforzando las dificultades de acceso de todos aquellos que no encajan en el molde del hombre blanco occidental a las instancias de participación política, que, de nuevo, son a su vez las únicas que permitirían modificar esta estrecha comprensión de la justicia. Lo que define a

${ }^{29}$ Fraser (2006), pp. 10-24 
esta perspectiva es su creencia en que es la transformación de los patrones de representación cultural lo que permitiría resolver las injusticias sociales. En este sentido, proponen la revaluación de subjetividades no respetadas y de sus producciones culturales, el reconocimiento y valoración de la diversidad cultural, entre otros. A su vez, ven en aquellos grupos de status con menor respeto, estima y prestigio que el resto de la sociedad el objeto de la afectación, y buscan la solución del problema de la igualdad a través de la revaluación de las valoraciones de status y, en sus versiones más radicales, la puesta en cuestión de los criterios en los que se asientan estas evaluaciones. ${ }^{30}$

Sin embargo, como muestra Fraser, resulta cuanto menos difícil, sino contraproducente, disociar las desigualdades materiales de las desigualdades simbólicas, puesto que éstas se potencian mutuamente y deben ser comprendidas como bidimensionales. Así, la clase explotada pierde reconocimiento, y las subjetividades despreciadas ven obstaculizado su acceso a los recursos. ${ }^{31}$ Esto resulta particularmente evidente en los esfuerzos del socialismo por construir una subjetividad de clase y del feminismo por redefinir la división del trabajo.

En este sentido, es preciso desfosilizar un ámbito privado en el que ni se redistribuye ni se reconoce, y para eso es a su vez necesario abrir la esfera pública a la efectiva participación de todos, ${ }^{32}$ de modo tal que la definición del alcance de los derechos y los recursos que deben ser redistribuidos, así como también de los patrones culturales que deben ser alterados, sea el resultado de un debate público al que todos tengamos acceso, en especial, los afectados por la medida estatal. ${ }^{33}$ Esto implica tres cambios fundamentales: (a) en lo que atañe a la igualdad, esta deja de ser concebida como un valor objetivo -en el sentido de definitivo- al cual debe acercarse el estado de cosas vigente, para pasar a ser el saldo provisorio de un debate que se encuentra abierto a la formulación de nuevos argumentos por aquellos que se encuentren excluidos; (b) en lo que atañe a la democracia, ésta deja de ser monopolizada por el parlamento, el que se convierte en una herramienta, entre otras, para la institucionalización de la misma; (c) la igualdad como tal debe ser construida en cada caso concreto, en tanto parece ser la única forma viable de admitir la participación de aquellos inmediatamente implicados en la situación de desigualdad. Finalmente (d), la interpretación del principio de igualdad, cuando opera como criterio reparador, debe adecuarse a la segmentación social que el

\footnotetext{
${ }^{30}$ Fraser (2006), pp. 16-24.

${ }^{31}$ Fraser (2006), p. 28.

${ }^{32}$ Esto se asienta sobre la idea habermasiana respecto de la cooriginariedad de las autonomías públicas y privadas.

${ }^{33}$ Fraser (2006), pp. 47-49.
} 
paradigma predominante ha producido. Esto resulta central para comprender los problemas habitualmente vinculados a la igualdad. El modelo de la igualdad formal posee, además de una posición predominante dentro de los ordenamientos jurídicos vigentes, una notable preponderancia en términos históricos, que, a su vez, ha influido sobre las estructuras sociales, generando la exclusión sistemática de grupos. ${ }^{34}$ Estas exclusiones colectivas -o estructurales- no sólo no pueden recibir una respuesta adecuada a través de una interpretación en clave individual del principio de igualdad, sino que, además, no deben ser obturadas en nombre de una paridad ficticia. ${ }^{35}$

La clave para la reconstrucción del principio de igualdad es, entonces, desde esta perspectiva, la participación, que incluye a la vez las demandas de redistribución y de reconocimiento. Nadie puede participar de una argumentación mientras se encuentre privado de condiciones mínimas de vida (redistribución) o bien, ni siquiera sea considerado un interlocutor válido (reconocimiento). Por otro lado, ninguna concreción del principio de igualdad puede ser considerada válida de modo definitivo, en un contexto democrático, sin la participación de aquellos que se encuentran en la situación concreta de disparidad, como es el caso en el contexto interamericano de los pueblos o comunidades indígenas.

\section{CASOS PARA RE-INTERPRETAR}

Si bien tomamos la base de un universo de 274 casos contenciosos, 20 opiniones consultivas y 403 medidas provisionales resueltas por la Corte IDH, sólo nos interesan aquellos casos en los que se tratan temas de pueblos originarios $y$, que según entendemos, pueden ser reconstruidos en clave de igualdad. En este universo no se incluyen las resoluciones sobre medidas precautorias. Nos interesó rastrear aquellos casos donde expresamente se enfrentaba a un problema de igualdad. Estos casos conforman los "casos nuevos", en comparación con los llamados "casos tradicionales" de violación de derechos que llegaron a la Corte IDH. El patrón es nuevo en tanto estos casos llegan a la Corte IDH; sin embargo, no es nuevo en tanto tipo de violación a los derechos, las violaciones a los derechos de los pueblos originarios se remontan a la época de la colonia y la conquista y persisten hasta la actualidad. Justamente que no hayan llegado anteriormente y en forma sistemática a la Corte IDH habla de las barreras estructurales que obturan el acceso a la justicia local e internacional de los pueblos originarios.

${ }^{34} S_{A B A}$ (2007), p. 167.

${ }^{35} \mathrm{~V}$. más adelante, análisis del voto en disidencia del juez Montiel Argüello en el caso YATAMA. 
Así, nos detendremos especialmente en dos grupos de casos paradigmáticos que proponemos leer bajo el prisma de igualdad ampliado bosquejado en este trabajo, por un lado,

a) Comunidad indígena Yakye Axa vs. Paraguay $2005,{ }^{36}$ Comunidad indígena Sawhoyamaxa vs. Paraguay 2006, ${ }^{37}$ Comunidad Indígena Xákmok Kásek vs. Paraguay $2010^{38}$ sobre condiciones de existencia para garantizar vida digna a una comunidad indígena y derecho de propiedad colectiva sobre tierras ancestrales ${ }^{39}$ y por el otro lado,

b) Yatama vs. Nicaragua $2005^{40}$ sobre derecho a ser elegidos como representantes de comunidades indígenas e interés legítimo del Estado de reglamentar las candidaturas para compararlo con el caso Castañeda Gutman vs. Estados Unidos Mexicanos 2008. ${ }^{41}$

\section{IV.1 La igualdad como condición: derecho a la propiedad colectiva y condiciones de existencia digna de una comunidad indígena}

El "patrón nuevo" de violación de los derechos requiere integrar la igualdad a su vez como prohibición por omisión, insuficiencia o defecto. En casos relativamente recientes, la Corte IDH se pronunció sobre condiciones de existencia y propiedad colectiva de las tierras para garantizar, además, condiciones de vida digna a una comunidad indígena.

Hablamos de "caso paradigmático" que entendemos se conforma paulatinamente por los contenidos ganados en casos como: ${ }^{42}$

- Comunidad indígena Yakye Axa vs. Paraguay 2005,

- Comunidad indígena Sawhoyamaxa vs. Paraguay 2006,

- Comunidad Indígena Xákmok Kásek vs. Paraguay 2010.

Si bien es cierto que la Corte IDH se había pronunciado, por lo menos, en dos casos anteriores sobre el tema del derecho a la propiedad colectiva de pueblos originarios,

\footnotetext{
${ }^{36}$ Corte IDH, caso de la Comunidad Indígena Yakye Axa Vs. Paraguay. Fondo, Reparaciones y Costas. Sentencia de 17 de junio de 2005. Serie C No 125.

${ }^{37}$ Corte IDH, caso Comunidad Indígena Sawhoyamaxa Vs. Paraguay. Fondo, Reparaciones y Costas. Sentencia de 29 de marzo de 2006. Serie C No 146.

${ }^{38}$ Corte IDH, Sentencia del 24 de agosto de 2010.

${ }^{39}$ V. además, Comunidad Mayagna Awas Tingni vs. Nicaragua 2001.

${ }^{40}$ Corte IDH, Caso Yatama vs. Nicaragua, Sentencia de 23 de junio de 2005.

${ }^{41}$ Corte IDH, Caso Castañeda Gutman vs. Estados Unidos Mexicanos, Sentencia de 6 de agosto de 2008.

${ }^{42}$ V. además - Comunidad Mayagna Awas Tingni vs. Nicaragua 2001.
} 
- Comunidad Mayangna (Sumo) Awas Tingni c. Nicaragua (2001), ${ }^{43}$

- Comunidad Moiwana c. Suriname (2005), ${ }^{44}$

nos centraremos en los tres dirigidos contra Paraguay, ya que incluye en la cuestión debatida ${ }^{45}$ la relación con la generación de condiciones de existencia digna que se viola por falta de acción estatal o insuficiente. ${ }^{46}$ Así, nuestro análisis implica una línea jurisprudencial más general referida a la generación de condiciones de existencia digna, por un lado, y, por el otro lado, la combinamos con asegurar el acceso al derecho a la propiedad colectiva que implica a la vez respetar el reconocimiento de la diversidad cultural respecto del derecho a la alimentación, al agua, a la salud para generar condiciones de existencia digna, entre otros.

Desde el caso "Villagrán Morales" sobre niños de la calle, la Corte IDH ha sostenido que el derecho a la vida y a la integridad física se viola también por omisión estatal, más precisamente, por incumplimiento de obligaciones positivas del Estado para generar condiciones que garanticen una vida digna, ya sea de niños, de personas detenidas, de personas internadas. ${ }^{47}$ De estas obligaciones estatales,

${ }^{43}$ Corte IDH, caso Comunidad Mayangna (Sumo) Awas Tingni c. Nicaragua, sentencia del 31 de agosto de 2001, Serie C, No. 79.

${ }^{44}$ Corte IDH, caso Comunidad Moiwana c. Suriname, sentencia de 15 de junio de 2005, Serie C No. 124.

${ }^{45}$ En los casos no se discute que la legislación paraguaya reconoce la existencia de los pueblos indígenas como grupos anteriores a la formación del Estado, así como la identidad cultural de estos pueblos, tampoco se discute la relación que tienen con su respectivo hábitat y las características comunitarias de su dominio sobre sus tierras, otorgándoles, además, una serie de derechos específicos, que sirven de base para que este Tribunal defina el alcance y contenido del artículo 21 de la Convención. Aún más, el Estado no niega que los miembros de la Comunidad Xákmok Kásek tienen el derecho a la propiedad comunitaria de su territorio tradicional, y que la caza, pesca y recolección sean elementos esenciales de su cultura. Así, la Corte IDH identifica que la cuestión es mucho más específica y se centra en la necesidad de restituir específicamente las tierras reclamadas por los miembros de la Comunidad y la realización efectiva del derecho a la propiedad. V. caso Comunidad Indígena Xákmok Kásek vs. Paraguay 2010, párr. 88-89.

${ }^{46}$ Clérico (2008).

${ }^{47}$ V. caso Villagrán Morales y Otros ("Niños de la Calle"), 1999; caso Bulacio, 2003; caso Myrna Mack Chang, 2003; caso del Instituto de Reeducación del Menor, 2004; caso Huilca Tecse, 2005; caso de los Hermanos Gómez Paquiyauri (2004: párr. 124); casos de Juan Humberto Sánchez (2003, párr. 110) y de los 19 Comerciantes (2004, párr. 153). Y referido a las condiciones de detención, v. caso del Penal Miguel Castro Castro (párrs. 285, 293 a 295, 300 y 301), caso Montero Aranguren y otros (Retén de Catia) (párrs. 102 y 103), caso De la Cruz Flores (párr. 132), caso Tibi (párr. 157), caso Loayza Tamayo; caso de la Masacre de Pueblo Bello, párr. 120; caso de la "Masacre de Mapiripán", párr. 232; caso Huilce Tecse, Sentencia de 3 de marzo de 2005, Serie C No. 121, párr. 66; caso "Instituto de Reeducación del Menor", Sentencia de 2 de septiembre de 2004, Serie C No. 112, párr. 158; caso de los Hermanos Gómez Paquiyauri, Sentencia de 8 de julio de 2004, Serie C No. 110, párr. 129; caso 19 Comerciantes, párr. 153; caso Myrna Mack Chang, párr. 153; caso Juan Humberto Sánchez, párr. 110; caso Bámaca Velásquez, Sentencia de 25 de noviembre de 2000. Serie C No 70, párr. 172; y caso de los "Niños de la Calle" (Villagrán Morales y otros), párrs. 144 a 146. 
que suenan generales, derivan deberes especiales, determinables en función de las particulares necesidades de protección del sujeto de derecho, ya sea por su condición personal o por la situación específica en que se encuentre, ${ }^{48}$ como extrema pobreza, marginación y niñez.

Ahora bien, en los tres casos paradigmáticos contra Paraguay, la Corte IDH amplía, según interpretamos, el sentido de generar las condiciones de existencia para garantizar vida digna a una comunidad indígena en relación con el derecho de propiedad colectiva sobre sus tierras. Los tres casos tratan de reclamos realizados por un colectivo que históricamente ha sido discriminado -tanto por el modelo distributivo como cultural dominante- y que las consecuencias perjudiciales de esa discriminación persisten en la actualidad.

La desigualdad estructural que padecen los pueblos originarios -y que está representada en el caso paradigmático de las comunidades indígenas de Paraguay- demuestra que no sólo se trata de una distribución desigual de los bienes económicos y sociales (acceso a sus tierras), sino también de una distribución desigualitaria de la palabra ${ }^{49}$ para determinar, para discutir, cuáles son las necesidades, sus intereses; por ejemplo, cómo quieren satisfacer su existencia de acuerdo con sus costumbres ancestrales ligadas al contacto con sus tierras, como lo advierte la Corte IDH en reiterada jurisprudencia:

"existe una tradición comunitaria sobre una forma comunal de la propiedad colectiva de la tierra, en el sentido de que la pertenencia de ésta no se centra en un individuo sino en el grupo y su comunidad. Los indigenas por el hecho de su propia existencia tienen derecho a vivir libremente en sus propios territorios; la estrecha relación que los indigenas mantienen con la tierra debe de ser reconocida y comprendida como la base fundamental de sus culturas, su vida espiritual, su integridad y su supervivencia económica. Para las comunidades indigenas la relación con la tierra no es meramente una cuestión de posesión $y$ producción sino un elemento material y espiritual del que deben gozar plenamente, inclusive para preservar su legado cultural y transmitirlo a las generaciones futuras". ${ }^{50}$

\footnotetext{
${ }^{48}$ Cfr. Caso de la Masacre de Pueblo Bello, párrs. 111 y 112; caso de la "Masacre de Mapiripán”, párrs. 108 y 110, y caso de los Hermanos Gómez Paquiyauri, Sentencia de 8 de julio de 2004, Serie C No 110, párr. 71.

${ }^{49}$ Estas advertencias alcanzan también al accionar de los tribunales. Por ejemplo, es fundamental que se posibilite el ejercicio real del derecho de los integrantes de los pueblos originarios a expresarse en su lengua materna, véase, sin embargo, "Informe sobre la audiencia pública celebrada en la Corte [argentina] sobre el caso 'Comunidad toba del Chaco"', diario Clarín, 07/11/2007.

${ }^{50}$ Caso "Comunidad Xákmok Kásek v. Paraguay", 2010, párr. 86, con cita de caso Comunidad Mayagna (Sumo) Awas Tingni Vs. Nicaragua. Fondo, Reparaciones y Costas. Sentencia de 31 de agosto de 2001, Serie C No 79, párr. 149; caso Comunidad Indígena Sawhoyamaxa Vs. Paraguay, párr. 118, y caso del Pueblo Saramaka. Vs. Surinam, párr. 90.
} 
En este punto, resulta pertinente volver sobre la propuesta de Fraser, ${ }^{51}$ que distingue (para luego combinarlas) dos concepciones amplias de la injusticia que generan desigualdades importantes. Como advertimos en el apartado III de este trabajo, la primera de ellas es la injusticia socioeconómica, arraigada en la estructura político-económica de la sociedad respecto de la distribución de bienes (ejemplos de este tipo de injusticia se pueden vislumbrar en la negación sistemática de los actores estatales y de los grupos económicos de los derechos de los pueblos indígenas sobre sus tierras, lo cual repercute en la privación de los bienes materiales indispensables para llevar una vida digna de acuerdo con sus costumbres). Así, la segunda es la injusticia cultural o simbólica, arraigada en los patrones sociales dominantes en una sociedad desde los que se interpreta, por ejemplo, cuáles son las necesidades de los pueblos originarios, sin que su voz sea escuchada en el proceso de decisión (ejemplos de este tipo de injusticia son la dominación cultural, el no reconocimiento y el irrespeto, e incluye la discriminación a pueblos originarios, entre otros, no basta con que el Estado "salga" a repartir alimentos, ${ }^{52}$ etc., es necesario que los pueblos originarios sean escuchados para que se "respete" las condiciones que posibilitan su autoabastecimiento, lo que implica escuchar sus necesidades e intereses desde otros patrones culturales que no responden al dominante del "hombre blanco occidental de clase media" que suele tener una visión mercantilista del uso y goce de los bienes)..$^{53}$

Así, los pueblos originarios no sólo son víctimas de una injusticia cultural o simbólica, sino también de una injusticia socioeconómica. La falta de consideración de sus identidades y de transferencia de sus tierras actúa conjuntamente para seguir produciendo desigualdad. Para remediarla, se requiere que las exigencias de reconocimiento cultural se integren con las pretensiones de redistribución socioeconómica. Padecen tanto la mala distribución socioeconómica como el erróneo y/o insuficiente reconocimiento cultural, sin que pueda entenderse

${ }^{51}$ Fraser (1997), p. 23.

52 Según informes de antropólogos que trabajan en las comunidades indígenas del Chaco y Formosa, "el hambre es el resultado de un problema integral cuya solución exige que las organizaciones y los mismos indígenas sean reconocidos como protagonistas". Diario Página 12, "Narrar el hambre", 13/10/07.

${ }^{53}$ Como advierte la Comisión en el caso, esto implica escuchar a los representantes de la Comunidad cuando agregan que "[l]a visión mercantilista del valor de las tierras, que es entendida únicamente como medio de producción para generar 'riquezas', es inadmisible e inaplicable cuando se aborda la cuestión indígena, pues supone una visión limitada de la realidad, al no contemplar [la] posibilidad de una concepción distinta a nuestra manera 'occidental' de ver las cosas del derecho indígena; sostener que sólo existe una forma de usar y disponer de los bienes, significaría hacer ilusoria la definición de que el Paraguay es un Estado pluricultural y multiétnico, echando por tierra los derechos de miles de personas que habitan el Paraguay y l[o] enriquecen con su diversidad”. Caso “Comunidad Xákmok Kásek v. Paraguay”, 2010, párr. 148. 
que alguna de estas injusticias es un efecto indirecto de la otra. Por eso, ni las soluciones redistributivas ni las soluciones de reconocimiento son suficientes por sí mismas. Es decir, sólo son respetuosas de los derechos de los pueblos originarios aquellas soluciones que implican una mejor distribución de los bienes económicos y sociales, pero que a su vez, los incluyan en el proceso de toma de decisiones y se tenga en cuenta su interpretación de sus necesidades, intereses y proyectos como comunidad..$^{54}$

Ahora bien, en los tres casos contra el Estado de Paraguay, las comunidades indígenas estaban viviendo fuera de ellas contra su voluntad, últimamente vivían en condiciones de miseria a la vera de una ruta. Esta situación de miseria de los miembros de la Comunidad está estrechamente vinculada a la falta de acceso a la propiedad comunitaria de sus tierras. ${ }^{55} \mathrm{~A}$ su vez, esto aniquila las posibilidades de autoabastecimiento y auto-sostenibilidad de sus miembros, de acuerdo con sus tradiciones ancestrales. ${ }^{56}$ Es decir, que la combinación del derecho a la propiedad y a una existencia digna afecta el derecho a la autonomía colectiva de la Comunidad:

"... la falta de sus tierras tradicionales y las limitaciones impuestas por los propietarios privados repercutió en los medios de subsistencia de los miembros de la Comunidad. La caza, pesca y recolección cada vez fueron más dificiles, llevaron a que los indígenas decidieran salir de la Estancia Salazar y reubicarse en "25 de Febrero" o en otros lugares, disgregándose asi parte de la Comunidad ... Todas estas afectaciones se incrementan con el transcurso del tiempo y aumentan la percepción de los miembros de la Comunidad de que sus reclamos no son atendidos.". 57

\footnotetext{
${ }^{54}$ Clérico (2008).

${ }^{55}$ Caso "Comunidad Xákmok Kásek v. Paraguay", 2010: El Tribunal recuerda su jurisprudencia respecto a la propiedad comunitaria de las tierras indígenas, según la cual: 1) la posesión tradicional de los indígenas sobre sus tierras tiene efectos equivalentes al título de pleno dominio que otorga el Estado; 2) la posesión tradicional otorga a los indígenas el derecho a exigir el reconocimiento oficial de propiedad y su registro; 3 ) el Estado debe delimitar, demarcar y otorgar título colectivo de las tierras a los miembros de las comunidades indígenas; 4) los miembros de los pueblos indígenas que por causas ajenas a su voluntad han salido o perdido la posesión de sus tierras tradicionales mantienen el derecho de propiedad sobre las mismas, aun a falta de título legal, salvo cuando las tierras hayan sido legítimamente trasladadas a terceros de buena fe, y 5) los miembros de los pueblos indígenas que involuntariamente han perdido la posesión de sus tierras, y éstas han sido trasladadas legítimamente a terceros inocentes, tienen el derecho de recuperarlas o a obtener otras tierras de igual extensión y calidad.

${ }^{56}$ V. Caso Comunidad Mayagna (Sumo) Awas Tingni Vs. Nicaragua. Fondo, Reparaciones y Costas, Sentencia de 31 de agosto de 2001. Serie C No 79, párr. 149; caso Comunidad Indígena Sawhoyamaxa Vs. Paraguay, párr. 118, y caso del Pueblo Saramaka. Vs. Surinam, párr. 90.

${ }^{57}$ Caso "Comunidad Indígena Xákmok Kásek v. Paraguay", con ref. a párr. 75 a 77, 79, 98. La afectación se incrementa pues afecta la identidad cultural de un grupo desaventajado relacionarlo con la paridad participativa.
} 
Y como sostiene la Corte IDH, esto los lleva a depender casi exclusivamente de las acciones estatales y verse obligados a vivir de una forma no solamente distinta a sus pautas culturales, sino en la miseria. Debido a las características de este caso paradigmático -conformado por los tres casos contra el Estado de Paraguay-, coincidimos con Cancado Trindade, cuando advierte sobre la centralidad que adquieren las víctimas por sobre la posición del Estado que invoca circunstancias presumiblemente eximentes de su responsabilidad. Sin embargo, la Corte IDH en su posición mayoritaria considera las razones y acciones realizadas por el Estado, aunque luego concluya que fueron insuficientes y violatorias de varios derechos de la Convención. Esta argumentación puede ser reconstruida en clave de examen de igualdad como prohibición de insuficiencia, aunque la Corte IDH no lo haya anunciado expresamente en su argumentación, sino en clave de conclusión.

"En el presente caso está establecido que la situación de extrema y especial vulnerabilidad de los miembros de la Comunidad se debe, inter alia, a la falta de recursos adecuados y efectivos que en los hechos proteja los derechos de los indígenas y no sólo de manera formal; la débil presencia de instituciones estatales obligadas a prestar servicios y bienes a los miembros de la Comunidad, en especial, alimentación, agua, salud y educación, y a la prevalencia de una visión de la propiedad que otorga mayor protección a los propietarios privados por sobre los reclamos territoriales indígenas, desconociéndose, con ello, su identidad cultural y amenazando su subsistencia física. Asimismo, quedó demostrado el hecho de que la declaratoria de reserva natural privada sobre parte del territorio reclamado por la Comunidad no tomó en cuenta su reclamo territorial ni tampoco fue consultada sobre dicha declaratoria. Todo lo anterior evidencia una discriminación de facto en contra de los miembros de la Comunidad Xákmok Kásek, marginalizados en el goce de los derechos que el Tribunal declara violados en esta sentencia. Asimismo, se evidencia que el Estado no ha adoptado las medidas positivas necesarias para revertir tal exclusión. Por lo expuesto y de conformidad con las violaciones de los derechos previamente declaradas, la Corte considera que el Estado no ha adoptado medidas suficientes y efectivas para garantizar sin discriminación los derechos de los miembros de la ComunidadXákmok Kásek, de conformidad con el artículo 1.1 de la Convención, en relación con los derechos reconocidos en los artículos 21.1, 8.1, 25.1, 4.1, 3 y 19 del mismo instrumento"..$^{58}$

La fórmula de la prohibición de insuficiencia en el examen de igualdad también dice: Es necesaria una protección "adecuada" -bajo consideración de los bienes

${ }^{58}$ Caso "Comunidad Indígena Xákmok Kásek v. Paraguay”. Cursiva y énfasis agregado. 
jurídicos que colisionan; será decisivo que la protección sea como tal "eficaz". Las medidas legislativas deben ser "suficientes" para alcanzar una protección "adecuada y eficaz" ... ${ }^{59}$ y así lograr un mejor trato igualitario.

La Corte IDH reitera en varios lugares de su argumentación que las acciones del Estado fueron "insuficientes" o que no eran "adecuadas", pero a nuestro entender no sólo para lograr el derecho a la propiedad colectiva de sus tierras, del derecho a la existencia digna en clave de autoabastecimiento, sino también respecto del derecho a ser tratados como iguales. Para ello, el Estado tiene la carga de la argumentación y de la justificación agravada. Tiene que demostrar y argumentar que las acciones positivas realizadas fueron idóneas, las más adecuadas para poner a los pueblos originarios en igualdad real de oportunidades para autodeterminarse, lo que implica por lo menos el autoabastecimiento y necesariamente el acceso a sus tierras. Veamos por qué las acciones estatales fueron evidentemente insuficientes y defectuosas y por qué el Estado del Paraguay violó los derechos de las comunidades indígenas.

\section{IV.1.1 Examen de idoneidad}

En el examen de igualdad por insuficiencia, el punto de partida del examen es, también, el examen de idoneidad/adecuación técnica. Como primer elemento se debe identificar la acción insuficiente atacada, que en el caso es compleja:

- por un lado, se trata del Decreto 1830 que declaró en estado de emergencia a la comunidad (M1') y

- por el otro lado, el procedimiento administrativo para recuperar las tierras (M1").

Respecto de ambos medios (M1' y M1") hay que examinar si el Estado demostró y argumentó que eran acciones positivas suficientes, además, para mejorar la situación de desigualdad no sólo en términos distributivos sino también de adecuación cultural (reconocimiento) (v. caso Yanomani, Res. 12/85, caso $\mathrm{N}^{\circ} 7615$ (Brasil), 5/5/1985, consid. No 10.).

Respecto de la generación de condiciones de existencia para garantizar derecho a la vida digna de la Comunidad (P1), la Corte IDH avanzó identificando las variables respecto de las cuales mediría argumentativamente si el Estado cumplió con la obligación de generar esas condiciones y de respetar el derecho a la propiedad comunal de las tierras ancestrales (P1'). ${ }^{60}$

\footnotetext{
${ }^{59}$ BVerfGE 88, 203 (254, 257, 265, 262).

${ }^{60}$ Caso "Comunidad Indígena Xákmok Kásek v. Paraguay", 2010: "Para determinar la existencia de la relación de los indígenas con sus tierras tradicionales, la Corte ha establecido que: i) ella puede expresarse de distintas maneras según el pueblo indígena del que se trate y las circunstancias concretas en que se
} 
Estas variables se leen en clave de Derechos Económicos, Sociales y Culturales (DESC):

- derecho de acceso al agua,

- derecho a la alimentación,

- derecho a la salud y

- derecho a la educación.

Respecto del derecho al acceso a agua: las gestiones realizadas por el Estado a partir del Decreto No 1830 no han alcanzado para proveer a los miembros de la Comunidad de agua en cantidad suficiente y calidad adecuada, lo cual los expone a riesgos y enfermedades.

Respecto del derecho a la alimentación: a pesar de lo demostrado por el Estado, no se superaron las necesidades nutricionales que, con anterioridad al Decreto No 1830 existían. Y muy probablemente, no se superen hasta tanto se implementen las medidas adecuadas y efectivas para el acceso real a sus tierras que implica también acceso a una alimentación que respete sus tradiciones y costumbres.

Respecto del derecho a la salud: si bien se reconocen los avances realizados por el Estado, las medidas adoptadas se caracterizan por ser temporales y transitorias. Además, el Estado no garantizó la accesibilidad física ni geográfica a establecimientos de salud para los miembros de la Comunidad. La distancia suele ser una barrera geográfica que implica una desigualdad estructural para toda la comunidad indígena no sólo en el caso analizado. ${ }^{61} \mathrm{~N}$ o se evidencian acciones positivas para garantizar la aceptabilidad de dichos bienes y servicios, ni que se hayan desarrollado medidas educativas en materia de salud que, a su vez, sean respetuosas de los usos y costumbres tradicionales (v. además, CIDH, Informe sobre pueblos indígenas, 27/2/2011, párr. 157 y Comité DESC, OG No 14, párr. 27), esto último sólo se entiende en el contexto de igualdad como reconocimiento. Por lo demás, miembros de la comunidad, en especial, niños

encuentre, y ii) la relación con las tierras debe ser posible. Algunas formas de expresión de esta relación podrían incluir el uso o presencia tradicional, a través de lazos espirituales o ceremoniales; asentamientos o cultivos esporádicos; caza, pesca o recolección estacional o nómada; uso de recursos naturales ligados a sus costumbres, y cualquier otro elemento característico de su cultura. El segundo elemento implica que los miembros de la Comunidad no se vean impedidos, por causas ajenas a su voluntad, a realizar aquellas actividades que revelan la persistencia de la relación con sus tierras tradicionales. En el presente caso, la Corte observa que la relación de los miembros de la Comunidad con su territorio tradicional se manifiesta, inter alia, en el desarrollo de sus actividades tradicionales dentro de dichas tierras".

${ }^{61}$ V. Informe presentado por Paul HunT (2005), par. 79. 
y ancianos murieron por causas de enfermedades evitables ${ }^{62}$ y que requieren tratamiento de bajo costo. ${ }^{63}$

Respecto del derecho a la educación: si bien algunas condiciones en cuanto a la prestación de la educación por parte del Estado han mejorado, no existen instalaciones adecuadas para la educación de los niños. Las clases se desarrollan bajo un techo sin paredes y al aire libre. Igualmente, no se asegura por parte del Estado ningún tipo de programa para evitar la deserción escolar.

En todos estos aspectos relevantes, M1 no fue suficiente ni adecuado. Al respecto, la Corte IDH evaluó el accionar estatal insuficiente, en parte, con estándares generales, por ejemplo, respecto del acceso al agua se refirió a los "estándares internacionales". Sin embargo, en "Yakye Axa” transitó claramente la ruta del reconocimiento y evaluó la falta de suficiencia de las medidas estatales en relación con la vinculación de la comunidad a su tierra ${ }^{64}$ en clave de DESC. ${ }^{65}$

${ }^{62}$ V. caso Sawhoyamaxa: "Como ha sido demostrado en el capítulo de Hechos Probados (párr. 73.74), la mayoría de los fallecidos en la Comunidad corresponde a niños y niñas menores de tres años de edad, cuyas causas de muerte varían entre enterocolitis, deshidratación, caquexia, tétanos, sarampión y enfermedades respiratorias como neumonía y bronquitis; todas enfermedades razonablemente previsibles, evitables y tratables a bajo costo".

${ }^{63}$ Sobre el Decreto No 3789, que declaró en estado de emergencia a la Comunidad Sawhoyamaxa: las medidas adoptadas por el Estado en cumplimiento de este decreto no pueden calificarse de suficientes y adecuadas. En efecto, durante más de seis años de vigencia del decreto, el Estado sólo entregó víveres a las presuntas víctimas en diez ocasiones, y medicamentos y materiales escolares en dos oportunidades, con extensos intervalos entre cada entrega (párr. 73.64 a 66). Estas entregas, así como las cantidades suministradas, son a todas luces medidas insuficientes para revertir la situación de vulnerabilidad y riesgo de los miembros de esta Comunidad y prevenir violaciones del derecho a la vida, tanto así que luego de la entrada en vigor del Decreto de emergencia al menos 19 personas fallecieron (párr. 73.74. 1, 5 a 16, 20, 22 y 27 a 30). V. asimismo, Parra Vera (2008, 343).

${ }^{64}$ Caso "Yakye Axa”, párr. 163: "la Corte debe establecer si el Estado generó condiciones que agudizaron las dificultades de acceso a una vida digna de los miembros de la Comunidad Yakye Axa y si, en ese contexto, adoptó las medidas positivas apropiadas para satisfacer esa obligación, que tomen en cuenta la situación de especial vulnerabilidad a la que fueron llevados, afectando su forma de vida diferente (sistemas de comprensión del mundo diferentes de los de la cultura occidental, que comprende la estrecha relación que mantienen con la tierra) y su proyecto de vida, en su dimensión individual y colectiva, a la luz del corpus juris internacional existente sobre la protección especial que requieren los miembros de las comunidades indígenas".

${ }^{65}$ Caso "Yakye Axa”, párr. 164: “... los miembros de la Comunidad Yakye Axa hubiesen podido abastecerse en parte de los bienes necesarios para su subsistencia de haber estado en posesión de sus tierras tradicionales. El desplazamiento de los miembros de la Comunidad de estas tierras ha ocasionado que tengan especiales y graves dificultades para obtener alimento, principalmente porque la zona que comprende su asentamiento temporal no cuenta con las condiciones adecuadas para el cultivo ni para la práctica de sus actividades tradicionales de subsistencia, tales como caza, pesca y recolección. Asimismo, en este asentamiento los miembros de la Comunidad Yakye Axa ven imposibilitado el acceso a una vivienda adecuada dotada de los servicios básicos mínimos, así como a agua limpia y servicios sanitarios”. 
Y en "Xákmok Kásek" realizó el examen teniendo en cuenta la "perspectiva etno-cultural". ${ }^{66}$

El punto fuerte del examen de la Corte IDH, en este último sentido de la igualdad, llegará de la mano del examen de M1" respecto del derecho a la propiedad colectiva de la Comunidad, aquí sí este medio no es probado con "lo esperable en general", sino con "lo esperable atendiendo a la relación de la Comunidad con su tierra". Veamos.

Respecto de la idoneidad de M1": la Corte reiteró, como en los casos de las comunidades indígenas de Yakye Axa y Sawhoyamaxa, que el procedimiento administrativo interno para la reivindicación de tierras tradicionales era inefectivo, por cuanto no ofrecía la posibilidad real de que los miembros de las comunidades indígenas recuperaran sus tierras tradicionales si éstas se encontraban bajo dominio privado. 67 La falta de idoneidad de M1" que implicaría la posibilidad real de acceso a sus tierras, provoca además, la ausencia de posibilidades de autoabastecimiento y autosostenibilidad de sus miembros, de acuerdo a sus tradiciones ancestrales, lo cual los lleva a depender casi exclusivamente de las acciones estatales y verse obligados a vivir de una forma no solamente distinta a sus pautas culturales, sino en la miseria.

La Corte IDH examina la idoneidad ${ }^{68}$ de M1 (que incluye M1' y M1"), no en general ni en abstracto, sino cotejándola con el caso concreto. ${ }^{69}$ Se trata de una aplicación intensiva del examen de idoneidad que viene dada porque la restricción a los derechos ${ }^{70}$ era

\footnotetext{
66 "Conforme a los estándares internacionales, los Estados tienen el deber de garantizar la accesibilidad a educación básica gratuita y la sostenibilidad de la misma. En particular, cuando se trata de satisfacer el derecho a la educación básica en el seno de comunidades indígenas, el Estado debe propiciar dicho derecho con una perspectiva etno-educativa. Lo anterior implica adoptar medidas positivas para que la educación sea culturalmente aceptable desde una perspectiva étnica diferenciada".
}

${ }^{67}$ Caso Comunidad Indígena Xákmok Kásek vs. Paraguay 2010. En virtud de que en el presente caso se trata del mismo recurso, ya que el Estado no ha modificado su legislación ni su práctica al respecto, el Tribunal reitera su jurisprudencia en relación a que el procedimiento administrativo bajo estudio presenta los siguientes problemas estructurales, que impiden que el mismo pueda convidarse efectivo: a) restricción en las facultades de expropiación; b) sometimiento del procedimiento administrativo a la existencia de un acuerdo de voluntad entre las partes, y c) ausencia de diligencias técnico-científicas tendientes a encontrar una solución definitiva del problema. Cfr. Caso Comunidad Indígena Yakye Axa Vs. Paraguay, párr. 98, y Caso Comunidad Indígena Sawhoyamaxa Vs. Paraguay, párr. 108.

${ }^{68}$ Sobre examen de idoneidad v. Clérico (2007a).

${ }^{69}$ En este punto consideramos que en materia de DESC hay un avance en comparación con el caso "5 Pensionistas", donde evalúa las mejoras en los derechos a la pensión en general y no en concreto.

${ }^{70}$ Los derechos de los pueblos originarios en el caso no son sólo DESC de prestación positiva en el sentido que generan obligaciones estatales de dar, de restituir, sino también obligaciones de organización y procedimiento. Por ello, si bien la Corte IDH no lo advierte expresamente aquí, está interpretando el derecho como derecho de organización y procedimiento que para poder ser ejercido requiere que el Estado cumpla con sus obligaciones de establecer procedimientos administrativos y judiciales eficaces para reclamar por sus 
desde el vamos extrema ${ }^{71}$ y el accionar estatal se requería de forma "urgente". ${ }^{72}$ Por ello también tiene la carga de la prueba de la idoneidad de sus acciones. $^{73}$

\section{IV.1.2 Examen del medio alternativo más suficiente}

En el examen del medio alternativo en la prohibición por insuficiencia en el examen de igualdad, se examina si otros medios pudieron ser implementados para evitar o disminuir a un grado tolerable la restricción por omisión a los derechos de la comunidad indígena y con ello, disminuir o hacer desaparecer la discriminación. Este examen complementa el de idoneidad porque la comparación permite determinar la medida de la acción suficiente.

En el caso, el medio alternativo suficiente (en comparación con M1' y M1") es para la Corte IDH, según interpretamos, facilitar el acceso a las tierras ancestrales o alternativas, pero que respeten la identidad cultural y el autoabastecimiento. En este sentido, hasta el propio Estado reconoce la existencia de este medio alternativo suficiente y adecuado, sin embargo, no demuestra acciones concretas de haberlo

tierras. Sobre la función de prestación positiva de los derechos y, además, sobre la función de organización y procedimiento, v. AleXY (1994, cap. 9); Clérico (2010); cfr. KingSTON (2010, p. 133).

${ }^{71} \mathrm{Y}$ aún incrementada por la duración de la afectación como se señaló anteriormente: “Todas estas afectaciones se incrementan con el transcurso del tiempo y aumentan la percepción de los miembros de la Comunidad de que sus reclamos no son atendidos". Caso Comunidad Indígena Xákmok Kásek vs. Paraguay 2010.

${ }^{72}$ V. Caso "comunidad Sawhoyamaxa vs. Paraguay" (2006): La Corte no acepta el argumento estatal referente a la responsabilidad compartida que tenían los enfermos de concurrir a los centros asistenciales para recibir tratamiento, y los líderes de la Comunidad de llevarlos a tales centros o comunicar la situación a las autoridades sanitarias. A partir de la emisión del Decreto de emergencia correspondía al INDI y a los Ministerios del Interior y de Salud Pública y Bienestar Social adoptar "las acciones que correspondan para la inmediata provisión de atención médica y alimentaria a las familias integrantes de [la Comunidad Sawhoyamaxa], durante el tiempo que duren los trámites judiciales referentes a la legislación de las tierras reclamadas como parte de [su] hábitat tradicional" (párr. 73.63). Con ello, los bienes y servicios de salud específicamente dejaron de depender de la capacidad adquisitiva individual de las presuntas víctimas, y por tanto, el Estado debió adoptar medidas que contribuyan a la prestación y suministro de tales bienes y servicios. Es decir, las medidas a las que el Estado se comprometió frente a los miembros de la Comunidad Sawhoyamaxa diferían por su carácter de urgencia de aquellas que el Estado debía adoptar para garantizar los derechos de la población y las comunidades indígenas en general. Aceptar lo contrario sería incompatible con el objeto y propósito de la Convención Americana, la cual requiere que sus provisiones sean interpretadas y aplicadas de tal forma que los derechos en ella contemplados sean práctica y efectivamente protegidos.

${ }^{73}$ Es necesario que el Estado demuestre que hizo las gestiones necesarias para sacar a los indígenas del costado de la ruta y, mientras eso sucedía, que adoptó acciones pertinentes para disminuir el riesgo en el que se encontraban (párr. 163). 
implementado. ${ }^{74}$ En suma, la restricción a la igualdad por acción insuficiente pudo haber sido evitada o disminuida en un grado soportable. ${ }^{75}$

\section{IV.1.3 Examen de proporcionalidad en sentido estricto}

En este punto la fórmula de la proporcionalidad, como en la prohibición por exceso, dice, cuanto más intensiva sea la restricción a la igualdad y a los derechos, en este caso, por acción insuficiente, tanto más importantes tienen que ser las razones que alegue el Estado para justificar sus omisiones. De un lado, tenemos una afectación extrema (es decir, más que grave $)^{76}$ del derecho a la vida digna relacionado con el derecho a la propiedad comunitaria de una comunidad indígena. La restricción extrema incluso se incrementa por la duración de la restricción, por la urgencia de la acción estatal frente al estado de emergencia ${ }^{77}$ y por pertenecer el grupo de afectados a un grupo vulnerable (argumento de igualdad); por ello

${ }^{74}$ Caso "Comunidad Indígena Xákmok Kásek vs. Paraguay" (2010). Propiedad ancestral. Tierras “alternativas": El Estado sostuvo que el derecho de los miembros de la Comunidad se podría satisfacer con tierras alternativas a las reclamadas, ya que las tierras tradicionales no se limitan a las tierras reclamadas. No obstante, el Estado no ha indicado cuáles serían estas tierras alternativas, de igual extensión y calidad, que pudieran satisfacer el reclamo de la Comunidad. Si bien aportó una lista de propiedades disponibles en las zonas cercanas al actual asentamiento de la Comunidad, no indicó las características o cualidades de las mismas que pudieran satisfacer los requisitos de calidad necesarios para la sustentabilidad de los Xákmok Kásek. No basta con que existan otras propiedades disponibles. Tal como indicó el perito presentado por el Estado, para el otorgamiento de tierras alternativas a las reclamadas, éstas deben al menos tener ciertas "aptitudes agroecológicas" y ser sometidas a un estudio que determine su potencial de desarrollo por parte de la Comunidad. V. párr. 104-107, entre otros.

${ }^{75}$ V. asimismo "Comunidad indígena Sawhoyamaxa vs. Paraguay 2006", párr. 164: "Al respecto, la Corte nota que la principal forma que el Estado tenía para trasladar a los miembros de la Comunidad fuera del costado de la ruta era entregarles sus tierras tradicionales. No obstante, como se desprende de los capítulos anteriores, el proceso administrativo tramitado ante el INDI y el IBR no ofreció garantías de una resolución efectiva y se mostró lento e ineficiente (párrs. 93 a 112). De allí que el Tribunal estableciera que el Estado no garantizó a los miembros de la Comunidad Sawhoyamaxa el derecho a la propiedad comunitaria ni a las garantías y protección judicial en un plazo razonable (párrs. 112 y 144). En otras palabras, si bien el Estado no los llevó al costado de la ruta, tampoco adoptó las medidas adecuadas, a través de un procedimiento administrativo rápido y eficiente, para sacarlos de allí y ubicarlos dentro de sus tierras ancestrales, en donde tendrían el uso y disfrute de sus recursos naturales, directamente vinculados con su capacidad de supervivencia y el mantenimiento de sus formas de vida".

${ }^{76} \mathrm{~V}$. modalidades de violación que pueden ser leídas en clave de intensidad de restricciones a los derechos de comunidades indígenas en "Comunidad indígena Sawhoyamaxa vs. Paraguay" (2006, voto de García Ramírez).

${ }^{77}$ En el presente caso, "las autoridades internas conocían de la existencia de una situación de riesgo real e inmediato para la vida de los miembros de la Comunidad. Consecuentemente, surgieron para el Estado determinadas obligaciones de prevención que lo obligaban -conforme a la Convención Americana (artículo 4º en relación con el artículo 1.1) y a su propio derecho interno (Decreto No 1830) - a la adopción de las medidas necesarias que, juzgadas razonablemente, eran de esperarse para prevenir o evitar ese riesgo", caso Comunidad Indígena Xákmok Kásek v. Paraguay 2010, párr. 192. V. caracterización de la prohibición de "exigir lo insoportable" por omitir lo esperable y la regla: (Zu), en CLÉRICO (2001), pp. 228, 246, 347, cap. 2.III.2.2.1.1.3, cap. 3.II.3). 
es claro desde el vamos que poco peso le puede asistir a las razones que el Estado intentó alegar para eximirse del cumplimiento suficiente de sus obligaciones. ${ }^{78}$ Por ejemplo, no alcanza con que alegue que las tierras reclamadas se encontraban siendo explotadas en forma racional por otros (una empresa), frente a "la especial relación de los miembros de la comunidad indígena reclamante con dicha tierra". De lo contrario, agrega la Corte IDH, "el derecho de reivindicación carecería de sentido y no ofrecería una posibilidad real de recuperar las tierras tradicionales. Limitar de esta forma la realización efectiva del derecho a la propiedad de los miembros de las comunidades indígenas no sólo viola las obligaciones del Estado derivadas de las disposiciones de la Convención relativas al derecho a la propiedad, sino que también compromete la responsabilidad del Estado en relación a la garantía de un recurso efectivo y constituye un trato discriminatorio que produce exclusión social. [Tampoco alcanza,] que la expropiación de las tierras reivindicadas hubiese sido denegada arguyéndose la explotación racional de las mismas y la supuesta afectación para la unidad productiva de la empresa ...., cuando de 10.700 hectáreas reclamadas, aproximadamente un total de 7.468 hectáreas fueron extraídas de la mencionada unidad productiva, ya sea porque se vendieron a otro propietario ... o porque se encuentran dentro del área declarada reserva natural privada que establece serias restricciones a su explotación ...”. ${ }^{79}$

\section{IV.2 Consideraciones intermedias}

En suma, de la aplicación del examen de igualdad (con sus tres pasos: idoneidad, medios alternativos y proporcionalidad) a la reconstrucción de estos casos paradigmáticos, surgen obligaciones para los Estados, entre otras, de adoptar las medidas necesarias para crear un marco normativo adecuado que disuada cualquier amenaza al derecho a la vida; establecer un sistema de justicia efectivo capaz de investigar, castigar y reparar toda privación de la vida por parte de agentes estata-

\footnotetext{
${ }^{78}$ Así, en el caso Comunidad indígena Sawhoyamaxa vs. Paraguay (2006, párr. 155) y en caso Comunidad Indígena Xákmok Kásek v. Paraguay 2010, párr. 188, sostiene: "Es claro para la Corte que un Estado no puede ser responsable por cualquier situación de riesgo al derecho a la vida. Teniendo en cuenta las dificultades que implica la planificación y adopción de políticas públicas y las elecciones de carácter operativo que deben ser tomadas en función de prioridades y recursos, las obligaciones positivas del Estado deben interpretarse de forma que no se imponga a las autoridades una carga imposible o desproporcionada. Para que surja esta obligación positiva, debe establecerse que al momento de los hechos las autoridades sabian o debian saber de la existencia de una situación de riesgo real e inmediato para la vida de un individuo o grupo de individuos determinados, y no tomaron las medidas necesarias dentro del ámbito de sus atribuciones que, juzgadas razonablemente, podían esperarse para prevenir o evitar ese riesgo". Caso de la Masacre de Pueblo Bello, párrs. 123 y 124.

${ }^{79}$ Caso Comunidad Indígena Xákmok Kásek vs. Paraguay 2010, párr. 149-150.
} 
$\operatorname{les}^{80}$ o particulares ${ }^{81}$, y salvaguardar el derecho a que no se impida el acceso a las condiciones que garanticen una vida digna ${ }^{82}$ de las personas individuales y/o de las comunidades indígenas, lo que incluye la implementación de medidas de acción positivas para prevenir la violación de estos derechos que en el caso de comunidades indígenas implica establecer medios eficaces para que puedan recuperar el derecho sobre sus tierras comunales ancestrales.

Esos medios eficaces no implican sólo procedimientos administrativos y judiciales. Si se analizan los pronunciamientos de los órganos del SIDH se concluye que esos procedimientos se refieren también a ámbitos de participación política. La Corte IDH y la CIDH han reiterado la obligación estatal de garantizar la consulta y participación de los pueblos indígenas en la determinación de acciones que afecten sus tierras. Esto implica además que "todos los miembros de la comunidad estén plena y cabalmente informados de la naturaleza y las consecuencias del proceso y se les brinde una oportunidad efectiva de participar individual o colectivamente". ${ }^{83} \mathrm{Sin}$ embargo, como las comunidades indígenas están atravesadas por una desigualdad estructural interpretamos que no alcanza con que se las consulte puntualmente sobre el acceso, posesión, uso de sus tierras, o "con la adopción de una ley" o "la creación de una institución pública" se requiere garantizar "la participación de los propios pueblos indígenas". ${ }^{84}$ Por ello, se requiere revisar la jurisprudencia de la Corte IDH cuando se trata de garantizar participación política de las comunidades indígenas empezando por uno de sus presupuestos mínimos, la posibilidad de someter sus candidatos al proceso eleccionario.

En suma, toda esta reconstrucción nos permite sostener que la insuficiencia de medidas estatales puede provenir de la falta de distribución de bienes económicos y sociales y, asimismo, de la insuficiencia por falta de reconocimiento, esto afecta la "paridad participativa" (en términos de Nancy Fraser) ${ }^{85}$ en términos de

\footnotetext{
${ }^{80}$ Cfr. Caso de la Masacre de Pueblo Bello, párr. 120.

${ }^{81}$ Cfr. Caso de la Masacre de Pueblo Bello, párr. 120; caso de la "Masacre de Mapiripán", párr. 111.

${ }^{82}$ Cfr. Caso Comunidad Indígena Yakye Axa, párr. 161; caso de los "Niños de la Calle" (Villagrán Morales y otros), párr. 144, y caso "Instituto de Reeducación del Menor", Sentencia de 2 de septiembre de 2004, Serie C No 112, párr. 156.

${ }^{83}$ Caso 11.140 Marry y Carrie Dann (EEUU de Norteamérica) Informe No 75/02 (fondo) del 27/12/2002, párr. 140 y cfr. Informe No 78/06 sobre admisibilidad de la petición 12.094, Comunidades aborígenes Lhaka Honahat (nuestra Tierra, Argentina), del 21/12/2006; Corte IDH, caso del Pueblo Saramaka, 28/11/2007, Serie C No 172, párrs. 133 y 134.

${ }^{84}$ Informe del Relator Especial sobre la situación de los derechos humanos y las libertades fundamentales de los indígenas, 27/2/2007, $\mathrm{A} / \mathrm{HRC} / 4 / 32$.

${ }^{85}$ Y según entendemos se ve reflejada en esta cita de la Corte IDH en el caso de Comunidad Indígena c. Paraguay 2010: "la pobreza limita gravemente, en la práctica, la capacidad de una persona o un grupo de personas
} 
participación democrática que nos lleva a su vez a la consideración del siguiente caso paradigmático.

\section{IV.3 La igualdad como objetivo: reglamentación electoral y participación de grupos subrepresentados}

La garantía de igual autonomía pública, entendida ésta como la igualdad de posibilidades en el acceso a las instancias de toma de decisiones políticas, es probablemente la pretensión más fundamental y a la vez la más audaz que pueda elevar un estado de derecho. Es la más fundamental, puesto que sobre ésta se asienta la legitimidad del ejercicio de la coacción que se arroga el Estado. Pero también la más audaz, en tanto abre la posibilidad de poner en cuestión, en los ordenamientos jurídicos vigentes, todas aquellas formas de dominación que no resisten el cuestionamiento de los oprimidos ${ }^{86}$ y que el derecho ha ido cristalizando de acuerdo a las relaciones de fuerza concretas que jalonaron $-y$ jalonan- el desarrollo de nuestras sociedades, opresiones que por momentos resultan difíciles de separar del estado de derecho mismo.

Parece relevante, sin embargo, trazar una distinción, cuanto menos conceptual, entre esta pretensión normativa, que nace con la Ilustración, pero que la excede -en tanto permite cuestionarla-, de los modos concretos en que el aparato estatal moderno intenta cumplirla. En otros términos, es preciso separar democracia de representación política, no tanto porque esta última no sea democrática, sino más bien, para evitar caer en el error de pensar que la segunda agota a la primera. ${ }^{87} \mathrm{De}$ este modo, la noción de autogobierno puede ser preservada cuanto menos como ideal regulativo, lo que nos permite, en primer lugar, establecer un criterio para evaluar los medios establecidos por los estados en este sentido, $y$, en segundo lugar, nos permite pensar la posibilidad de reconocer otras formas de autogobierno, en

de ejercer el derecho de participar en todos los ámbitos de la vida cultural y de tener acceso y contribuir a ellos en pie de igualdad y, lo que es más grave, afecta seriamente su esperanza en el porvenir y su capacidad para el disfrute efectivo de su propia cultura", que toma de Comité de Derechos Económicos, Sociales y Culturales, ONU, Observación General No 21, diciembre 21 de 2009, E/C.12/GC/21, párr. 38.

${ }^{86}$ Hombres sobre mujeres, propietarios sobre trabajadores, heterosexuales sobre homosexuales y occidentales sobre el resto, entre otras.

${ }^{87}$ Lo que nos conduciría a la falsa oposición, desarrollada por el liberalismo, entre democracia y derechos fundamentales. V. SABA (2007). En este sentido, lo más que puede reclamar para sí la representación y su estructura de partidos es su mayor adecuación al ideal de democracia frente a un gobierno de facto, lo que no es poco si tenemos en cuenta que el régimen representativo se inserta en un medio -el Estado, centralizado, soberano y coactivo- que por trayectoria y definición le es hostil, pero no puede pretender mantener esta preponderancia frente a las demandas de la ciudadanía, sea que se articulen a través de vías informales, como la protesta o la manifestación pública, o de vías formales, como el cuestionamiento en sede judicial de las leyes y las políticas públicas. 
un esquema que se acomoda mejor a la diversidad de culturas que la DADH se propone abarcar.

En este sentido, nos interesa analizar el problema de la igualdad en el acceso a las candidaturas políticas, que en el marco de la democracia representativa constituyen la forma predominante y privilegiada de participación política, haciendo de la competencia electoral entre partidos, regulada por el Estado, la primera respuesta de nuestros ordenamientos jurídicos a la pregunta por la democracia.

Es en esta brecha que se insertan las demandas presentadas ante la Corte IDH en los casos Yatama vs. Nicaragua y Castañeda Gutman vs. Estados Unidos Mexicanos, puesto que en ambos el tribunal está llamado a pronunciarse respecto del sistema representativo; sin embargo, bajo circunstancias diferentes:

- en YATAMA se trataba de la exclusión de los candidatos a alcaldes, vicealcaldes y concejales presentados por un partido político regional indígena para una elección local. ${ }^{88}$ Así, quedaron sólo seis partidos políticos para participar en las elecciones municipales. Según informes y testimonios, en algunas zonas se registró un nivel de abstencionismo de aproximadamente $80 \%$, dado que una parte del electorado, compuesto por miembros de comunidades indígenas y étnicas, no se encontraba debidamente representado por los partidos nacionales. ${ }^{89}$ Los candidatos que ganaron las

${ }^{88}$ La Comisión presentó la demanda para que la Corte IDH decidiera si el Estado violó los artículos $8^{\circ}$ (Garantías Judiciales), 23 (Derechos Políticos) y 25 (Protección Judicial) de la Convención Americana, todos ellos en relación con los artículos 1.1 (Obligación de Respetar los Derechos) y 20 (Deber de Adoptar Disposiciones de Derecho Interno) de dicho tratado, en perjuicio de los candidatos a alcaldes, vicealcaldes y concejales presentados por el partido político regional indígena Yapti Tasba Masraka Nanih Asla Takanka ("YATAMA"). La Comisión alegaba que dichas personas fueron excluidas de participar en las elecciones municipales realizadas el 5 de noviembre de 2000 en las Regiones Autónomas del Atlántico Norte y del Atlántico Sur (en adelante "la RAAN" y "la RAAS"), como consecuencia de la resolución emitida el 15 de agosto de 2000 por el Consejo Supremo Electoral. En la demanda se indicó que las presuntas víctimas presentaron diversos recursos contra dicha resolución y, finalmente, el 25 de octubre de 2000, la Corte Suprema de Justicia de Nicaragua declaró improcedente un recurso de amparo interpuesto por éstos. La Comisión señaló además que el Estado no previó un recurso que hubiese permitido amparar el derecho de dichos candidatos de participar y ser elegidos en las elecciones municipales de 5 de noviembre de 2000, como tampoco adoptó medidas legislativas o de otro carácter que fuesen necesarias para hacer efectivos tales derechos, especialmente no previó "normas en la ley electoral, en orden a facilitar la participación política de las organizaciones indígenas en los procesos electorales de la Región Autónoma de la Costa Atlántica de Nicaragua, de acuerdo al derecho consuetudinario, los valores, usos y costumbres de los pueblos indígenas que la habitan".

${ }^{89}$ Cfr. Observación Electoral en Nicaragua: elecciones municipales 2000/Unidad para la Promoción de la Democracia, Serie Américas, No 27, Secretaría General de la Organización de los Estados Americanos y Second Report. The Carter Center Mission to Evaluate Electoral Conditions in Nicaragua, November 1-8, 2000 (expediente de anexos a la demanda, tomo II, anexos 19 y 20, folios 651 y 715 ). 
elecciones pertenecían a los partidos tradicionales ${ }^{90}$. Justamente, la pregunta en el caso es si la aplicación de la Ley Electoral vigente al $2000^{91}$ y la exigencia de los requisitos para constituir un partido político disminuyeron las posibilidades de participación de las organizaciones indígenas y étnicas, convirtiéndose en una discriminación en contra de un grupo históricamente desaventajado.

- en Castañeda Gutman, en cambio, se trataba de una persona conocida en la dirigencia política mexicana que pretendió sin éxito en el orden interno que se inscribiera su candidatura independiente a la Presidencia de México para las elecciones que se celebraron en julio de 2006. La pregunta en el caso giraba en torno a determinar si el Estado violaba derechos políticos de la supuesta víctima frente a la inexistencia en el ámbito interno de un recurso sencillo y efectivo para el reclamo de la constitucionalidad de los derechos políticos por el consecuente impedimento para que Castañeda Gutman se presentara como candidato por fuera de un partido político.

Los artículos en juego de la Convención Americana son en ambos casos el 23, entre otros, que garantiza a todos los ciudadanos la participación en la dirección de los asuntos públicos, ya sea de modo directo o a través de representantes, el derecho a votar y ser elegido y de acceder en condiciones de igualdad a los cargos públicos.

Aun cuando el examen de proporcionalidad se encuentra desarrollado en Castañeda (2008), los argumentos desarrollados en YaTAMA (2005) son retomados en el último caso, de modo tal que es factible extraer, a partir de ambas sentencias, una regla uniforme en materia de restricciones reglamentarias a los derechos de

\footnotetext{
${ }^{90}$ Cfr. Second Report. The Carter Center Mission to Evaluate Electoral Conditions in Nicaragua, November 1-8, 2000 (expediente de anexos a la demanda, tomo II, anexo 20, folio 715); artículos periodísticos publicados en "El Nuevo Diario", titulados "YATAMA afuera", de 27 de octubre de 2000; "YATAMA preocupa a la OEA", de 28 de octubre de 2000, y "Policía cree que puede controlar a los Yatama", de 31 de octubre de 2000 (expediente de anexos a la demanda, tomo II, anexo 22, folios 796, 798 y 802); y solicitud de nulidad de las elecciones en la RAAN presentada el 8 de noviembre de 2000 ante el Consejo Supremo Electoral por el Partido Frente Sandinista de Liberación Nacional (PFSLN), Partido Liberal Constitucional (PLC), Partido Movimiento de Unidad Costeña (PAMUC), el Partido Indígena Multiétnico (PIM), el Partido Camino Cristiano Nicaragüense (CCN) y el Partido Conservador de Nicaragua (PCN) (expediente de anexos a la demanda, tomo II, anexo 22, folio 846).

${ }^{91}$ Más precisamente, el artículo 82 de la Ley Electoral de 2000 disponía como requisito para participar en las elecciones municipales que los partidos políticos presentaren candidatos al menos en el $80 \%$ de los municipios de la respectiva circunscripción territorial y respecto del $80 \%$ del total de las candidaturas. Así, el Consejo Supremo Electoral decidió no registrar a los candidatos propuestos por YATAMA. Consideró que, al quedar excluido el partido que se presentó en alianza con YATAMA, este último, por sí solo, no cumplía el requisito de haber presentado candidatos en el $80 \%$ de los municipios de la circunscripción territorial.
} 
participación política. ${ }^{92}$ El examen de la Corte IDH se concentra en la reglamentación de la presentación de candidaturas para cubrir cargos políticos.

\section{IV.3.1 Examen leve}

Con el objetivo de reconstruir la fórmula y alcances del mandato de igualdad en lo que atañe a la participación política en la jurisprudencia de la Corte IDH puede resultar útil recurrir nuevamente a la distinción entre patrones de violación de los derechos humanos propuesta por García Ramírez. ${ }^{93}$ En este sentido, el examen involucra dos posibles niveles de intensidad, a saber, uno de mínima, que podríamos denominar de la democracia representativa en sentido estricto, y otro de máxima, que podríamos denominar de la democracia como autogobierno.

El examen de menor intensidad de la vigencia del mandato de igualdad en el ejercicio de los derechos políticos implica para los estados partes garantizar el derecho al voto y la estructura de partidos políticos. Así afirma la Corte IDH que la democracia representativa constituye un principio fundamental del sistema interamericano, ${ }^{94}$ que los derechos a ser elegido y votar son las expresiones individuales y sociales de la participación política, ${ }^{95}$ que el voto es uno de los elementos esenciales para la existencia de la democracia ${ }^{96}$ y que los estados pueden establecer estándares mínimos para regular la participación política. ${ }^{97}$ En el caso Castañeda Gutman, la exigencia de adscripción partidaria para presentarse a una candidatura es considerada idónea en tanto los estados poseen un margen para la reglamentación del sistema democrático, ${ }^{98}$ y la Corte IDH considera que en el caso concreto de México, la misma apunta a garantizar el acceso de los ciudadanos al ejercicio del poder público en condiciones de igualdad y de manera eficaz. ${ }^{99}$ En lo que hace a la necesidad de la medida, la Corte IDH considera suficientes los argumentos presentados por el Estado mexicano, en el sentido de que la regulación en cuestión no implicaba un obstáculo concreto y específico para la postulación

\footnotetext{
${ }^{92}$ No obstante, algunas diferencias relevantes en los hechos son analizadas nuevamente hacia el final de la sección.

${ }^{93}$ Ver sección IV.1 en este artículo.

${ }^{94}$ Corte IDH, Caso Yatama vs. Nicaragua, par. 192.

${ }^{95}$ Corte IDH, Caso Yatama vs. Nicaragua, par. 197.

${ }^{96}$ Corte IDH, Caso Yatama vs. Nicaragua, par. 198.

${ }^{97}$ Corte IDH, Caso Yatama vs. Nicaragua, par. 207.

${ }^{98}$ Corte IDH, Caso Castañeda Gutman vs. Estados Unidos Mexicanos, par. 180 y 181.

${ }^{99}$ Corte IDH, Caso Castañeda Gutman vs. Estados Unidos Mexicanos, par. 183.
} 
del demandante. ${ }^{100}$ Por último y en lo que hace a la proporcionalidad en sentido estricto de la restricción, y teniendo en cuenta que se trata de elecciones de nivel federal, la Corte IDH considera que, no obstante los problemas de representación que afectan a los partidos políticos, la medida se encuentra justificada, puesto que la intensidad de la vulneración del derecho del demandante no es suficiente para justificar la suspensión de la medida. Con este criterio, la Corte IDH parece apuntar a que, por contraste con un gobierno de facto o bien con una democracia meramente formal, la posibilidad de participar en el proceso electoral constituye un piso mínimo de institucionalidad democrática que debe ser respetado. Esta regla, sin embargo, debe ser entendida en el contexto latinoamericano, ya no dominado - pero aún amenazado- por las sombras del golpe de Estado. ${ }^{101}$

\section{IV.3.2 Examen intenso}

Sobre este estándar mínimo, la Corte IDH elabora un examen de igualdad más intenso, según el cual la participación política puede incluir amplias y diversas actividades, realizadas de modo individual o colectivo, destinadas a intervenir ya en la designación de los representantes, ya en la formación de la política estatal de modo directo, ${ }^{102}$ la efectivización de los derechos políticos puede a su vez requerir medidas de acción positiva por parte del Estado, que exceden la mera reglamentación del sistema de partidos, ${ }^{103}$ el contenido esencial de estos derechos implica la participación efectiva de las personas en la conducción del Estado. ${ }^{104}$ Se promueve, además, el diseño de instancias destinadas a facilitar la participación de sectores específicos de la sociedad ${ }^{105}$ y la exigencia de pertenecer a un partido político no puede obstaculizar la participación política de los ciudadanos, ${ }^{106}$ puesto que se reconoce que existen otras formas de organización política cuya legitimidad no sólo ha sido reconocida, ${ }^{107}$ sino que además, en los casos de grupos subrepresentados, se convierten en vehículos esenciales de la manifestación política legítima. A través del segundo criterio, la Corte IDH introduce la desigualdad estructural como variable relevante, aumentando la intensidad del control en la aplicación del

\footnotetext{
${ }^{100}$ Corte IDH, Caso Castañeda Gutman vs. Estados Unidos Mexicanos, par. 202.

101 Honduras y más recientemente, Ecuador.

${ }^{102}$ Corte IDH, Caso Yatama vs. Nicaragua, par. 196.

${ }^{103}$ Corte IDH, Caso Yatama vs. Nicaragua, par. 201.

${ }^{104}$ Corte IDH, Caso Yatama vs. Nicaragua, par. 206.

${ }^{105}$ Corte IDH, Caso Yatama vs. Nicaragua, par. 207.

${ }^{106}$ Corte IDH, Caso Yatama vs. Nicaragua, par. 208.

${ }^{107}$ Corte IDH, Caso Yatama vs. Nicaragua, par. 215.
} 
examen de proporcionalidad. En este sentido, se tiene en cuenta la pertenencia de las víctimas a comunidades indígenas, ${ }^{108}$ para las cuales la estructura de partidos resulta ajena, ${ }^{109}$ que son un caso excepcional dentro de las organizaciones políticas, ${ }^{110}$ que de negarse la presentación de dichos candidatos se estaría desconociendo el derecho a elegir de los electores indígenas, ${ }^{111}$ que YATAMA contribuye a establecer y preservar la identidad cultural de los miembros de las comunidades indígenas y étnicas. ${ }^{12}$ De este modo, la Corte IDH toma un camino intermedio entre los extremos representados por los votos de los jueces A. Montiel Argüello y O. Jackman en la sentencia del 2005.

El primero (Montiel Argüello) sostiene una interpretación formal del principio de igualdad que lo conduce a sostener que el estado de Nicaragua "no puede tener leyes diferentes para cada una de las etnias que lo integran cuando se trata de la elección de autoridades que ejercerán sus funciones en territorios habitados por diferentes etnias como son los Municipios de las Regiones Autónomas". ${ }^{113}$ Esto nos habla de una lectura miope del principio de igualdad que resulta doblemente desigualitaria. En primer lugar, porque niega el trato diferencial intrínseco a una legislación, de cuyas instancias de producción los demandantes han sido sistemáticamente excluidos. ${ }^{114}$ Trato diferencial que, por otro lado, surge con toda la fuerza de los hechos en el caso, toda vez que la legislación defendida por la disidencia ha producido altos niveles de abstencionismo en regiones donde las comunidades indígenas representan un $80 \%$ de la población. En segundo lugar porque, al negar las desigualdades de partida, deja en manos de los sectores sociales predominantes las instancias de producción del derecho desde las cuales estas desigualdades pueden ser solucionadas. ${ }^{15}$ De este modo, se confunde democracia como autogobierno con democracia como aquel régimen que cada Estado haya adoptado, produciendo un "círculo vicioso" en términos de representación política que impide la introducción de nuevas voces al proceso democrático.

${ }^{108}$ Corte IDH, Caso Yatama vs. Nicaragua, par. 202.

${ }^{109}$ Corte IDH, Caso Yatama vs. Nicaragua, par. 218.

${ }^{110}$ Corte IDH, Caso Yatama vs. Nicaragua, par. 219.

${ }^{111}$ Corte IDH, Caso Yatama vs. Nicaragua, par. 226.

112 Corte IDH, Caso Yatama vs. Nicaragua, par. 227.

${ }^{113}$ Corte IDH, Caso Yatama vs. Nicaragua, voto Montiel Argüello, par. 5.

${ }^{114}$ En el caso de los pueblos indígenas, la miopía de la argumentación es todavía más intensa, puesto que la exclusión persistente y sistemática de los mismos es un hecho ampliamente reconocido, cuanto menos en términos simbólicos, por todas las sociedades latinoamericanas.

115 Patente en el parágrafo 10 de su voto. 
El segundo voto (Jackman), en el otro extremo, sostiene que la utilización de categorías tales como la de grupos desaventajados puede resultar problemática, en tanto reduciría la protección brindada por la Convención a aquellos ciudadanos que no son reconocidos como tales. ${ }^{116}$ Esta argumentación es similar a la comentada en el párrafo anterior, en tanto se asienta en una comprensión universalista de la ciudadanía, pero desde una perspectiva que no es la mera preservación de un estado de cosas político, sino más bien la búsqueda de un aumento en la intensidad de la participación política de la ciudadanía. Que sus argumentos no formen parte del voto mayoritario permite a la vez dar cuenta de la decisión de la Corte IDH en el caso Castañeda Gutman, cuya pretensión es rechazada en tanto el demandante no logra probar que forma parte de un grupo desaventajado, aún más, siendo éste un integrante conocido de la dirigencia política mexicana.

A partir de estos dos votos es posible reconstruir y determinar los alcances de la regla establecida por la Corte IDH del siguiente modo:

- En primer lugar, la reglamentación del sistema electoral por parte de los estados parte de la Convención, siempre que se adecue razonablemente a los parámetros de la democracia representativa, cuenta con una presunción de legitimidad, y es objeto de un escrutinio laxo o poco intensivo por parte del tribunal, no obstante lo cual parece quedar en cabeza del demandante la carga de la argumentación respecto de la vulneración concreta del derecho. ${ }^{117}$ - En segundo lugar, la regla parece reconocer una excepción en el caso de grupos evidentemente desaventajados, de modo tal que se habilita un examen intensivo de la razonabilidad de la medida. En este caso es el Estado el que debe demostrar que el medio seleccionado no vulnera el principio de igualdad.

Este "doble estándar" de la Corte puede ser interpretado a partir del criterio de "paridad participativa" desarrollado por N. Fraser (2006). En este sentido, el compromiso entre la eficacia de un sistema de organización político estatal y una comprensión seria de la democracia como autogobierno puede ser saldado a favor de la segunda, toda vez que aquellos que demandan puedan mostrar que su objetivo es aumentar la participación en condiciones de igualdad con el resto de la ciudadanía.

Las sentencias, sin embargo y en función de las diferentes circunstancias en las que surgen las demandas, dejan abierta una serie de interrogantes. ${ }^{118}$ Por ejemplo,

\footnotetext{
${ }^{116}$ Corte IDH, Caso Yatama vs. Nicaragua, voto concurrente de O. Jackman, parágrafo 4.

${ }^{117}$ En general, la argumentación de la Corte IDH no parece negar de plano la posibilidad de que exista una vulneración del derecho en el caso Castañeda Gutman, sino que se limita a afirmar que el demandante no ha logrado demostrarla.

${ }^{118}$ Resulta central en la argumentación de la Corte IDH que los demandantes en el caso YATAMA integren un colectivo indígena y que en el caso Castañeda Gutman se trate de un miembro reconocido de la clase política mexicana.
} 
si un grupo indígena hubiese demandado la posibilidad de participar en elecciones de nivel nacional a través de sus propias estructuras organizativas, o a la inversa, si un ciudadano hubiese demandado la posibilidad de participar en elecciones municipales por fuera de los partidos políticos, ¿cuál hubiese sido la respuesta de la Corte IDH? ¿Qué ocurre con aquellos grupos que, siendo fácticamente discriminados, aún no han alcanzado una presencia simbólica suficiente firme en el espacio público y no logran, por ende, ser visibilizados como un grupo excluido? En este sentido, podemos decir que ambas sentencias constituyen un avance de la jurisprudencia interamericana en términos de igualdad en la participación política, pero no por ello pueden ser consideradas como una respuesta definitiva a las fricciones que se generan entre un espacio público estatal y un espacio público político propiamente dicho.

\section{Conclusiones}

Como hemos advertido al comienzo de este trabajo, nuestro objetivo no perseguía realizar un abordaje integral de la jurisprudencia de la Corte IDH en materia de derechos indígenas. Seleccionamos algunas sentencias paradigmáticas que nos permitieron aplicar el examen de igualdad, articulándolo con las nociones de redistribución y reconocimiento. La reconstrucción y análisis de estas sentencias de la Corte IDH nos sirvió así para mostrar de qué modo dichas nociones resultan insumos conceptuales imprescindibles, en orden a dar cuenta de la argumentación normativa relativa a la aplicación del principio de igualdad. Tanto en los casos referidos a la posesión de la tierra, como en aquellos referidos a la presentación de candidaturas, la Corte IDH va más allá de los criterios de igualdad formal y material, desglosando el problema de los patrones económicos y culturales dominantes.

Como adelantamos en la sección II, las fórmulas de igualdad suponen dos clases de reclamos, a saber, (a) quien es tratado como diferente quiere ser tratado como igual, y (b) quien es tratado como igual quiere ser tratado como diferente. Lo que las sentencias analizadas ponen de manifiesto es que en ambos casos se trata, en realidad, de dos perspectivas sobre un mismo reclamo igualitario que deben ser distinguidas: Si en ambos casos los pueblos originarios reclaman un trato diferencial, ya sea en lo que atañe al acceso a la tierra o a las candidaturas políticas, es porque exigen gozar en igualdad de condiciones de sus autonomías privadas y públicas. Que los estados intenten, en ambos casos, defender el rechazo de ambos reclamos en nombre de una igualdad formal o material -aduciendo la mera distribución de recursos o bien la posibilidad de que presenten 
sus candidatos en las mismas condiciones que los partidos políticos- implica el desconocimiento de la desigualdad estructural a la que han sido -y siguen siendo- sometidas dichas comunidades.

Todo esto muestra que el derecho de los pueblos originarios a la restitución de sus tierras ancestrales se encuentra íntimamente vinculado al derecho de los mismos a una vida digna, que requiere a su vez del reconocimiento de sus patrones culturales en orden a ser adecuadamente satisfecho. De modo análogo, la reglamentación de la participación electoral no puede ser considerada válida toda vez que implique el desconocimiento de las formas de organización propias de los pueblos originarios. Es en este sentido que la Corte IDH destaca que uno de los aspectos de la insuficiencia de las acciones adoptadas por el Estado de Paraguay radica en la ausencia de acciones positivas tendientes a garantizar la "aceptabilidad" de los mismos por parte de los pueblos originarios. Otro tanto puede afirmarse de la decisión de la Corte IDH en el caso YATAMA, en tanto la reglamentación de la presentación de candidaturas es atacada, en tanto desconoce las formas de organización propias de las comunidades involucradas, condicionando el ejercicio de sus derechos políticos a la adaptación a estructuras partidarias que les son ajenas.

Como afirma la tesis de este trabajo, la aplicación del principio de igualdad en situaciones de desigualdad estructural no sólo requiere de un examen intenso de los argumentos del Estado. En tanto éstas implican la existencia de patrones culturales y materiales hegemónicos pero no universales, toda argumentación que tome en serio el principio de igualdad debe tomar en cuenta, de modo integrado, los déficits de redistribución y de reconocimiento. Sólo a partir del reconocimiento de ambos resulta posible conmover los patrones de dominación que atraviesan a nuestras sociedades y que no pueden, por ende, ser resueltos desde una perspectiva que confunda universalidad con predominio. Parafraseando a R. Alexy, el debate democrático no debe ser un debate "sobre" los ciudadanos, sino un debate "con" ellos, ${ }^{119}$ pero para que este "con" sea posible es preciso garantizar la paridad en la participación de todos, en especial, la de los afectados por la medida estatal y la de los excluidos.

Pero para que este "con" sea posible, es preciso someter constantemente a revisión crítica el alcance de la paridad en la participación, revisión que sólo puede cobrar sentido a partir de la inclusión de las voces de los excluidos -y no simplemente de una interpretación de sus intereses.

${ }^{119}$ AleXY (2006). 


\section{BibLiografíA}

Abreut De Begher, Liliana (2010): Propiedad Indígena (Buenos Aires, Editorial La Ley).

AldaO, Martín; RonConi, Liliana (2011): "Comentario al caso Karen Atala e hijas contra el Estado de Chile" en Derecho de Familia. Revista Interdisciplinaria de Doctrina y Jurisprudencia, en prensa.

Alexy, Robert (1986): Theorie der Grundrechte (Frankfurt am Main, Suhrkamp).

AleXY, Robert (2006): "Ley fundamental y teoría del discurso", en Cardinaux. N. [et al.] (coord.) Las razones de la producción del derecho (Buenos Aires, Facultad de Derecho-UBA).

Alexy, Robert (2009): "Zur Struktur der Grundrechte auf Schutz" (Sobre los derechos fundamentales a protección), en Derechos Sociales y ponderación (Madrid, Fundación Coloquio Jurídico Europeo).

ARENDT, Hannah (2006): Sobre la revolución (Madrid, Alianza).

Bernal Pulido, Carlos (2007): El principio de proporcionalidad y los derechos fundamentales (Madrid, Centro de Estudios Constitucionales).

Bianchi, Enrique, y Gullco, Hernán (2001): "La cláusula de igualdad: hacia un escrutinio más exigente”, en Jurisprudencia Argentina (Vol. I), p. 1241.

Clérico, Laura (2001): Die Struktur der Verhältnismäßigkeit (Baden-Baden, Nomos).

ClérICO, Laura, y SCHVARTZMAN, Sebastián (2007): “'Repetto’ re-visitado: a propósito del fallo del Tribunal Superior de la Ciudad de Buenos Aires sobre acceso a la docencia en el caso de los extranjeros", en Alegre, Marcelo, y Gargarella, Roberto (comp.) El derecho a la igualdad. Aportes para un constitucionalismo igualitario (Buenos Aires, LexisNexis), pp. 345-367.

Clérico, Laura (2007a): "El examen de proporcionalidad: entre el exceso por acción y la insuficiencia por omisión o defecto", en Carbonell, M. (ed.), El principio de proporcionalidad en el Estado constitucional (Bogotá, Universidad del Externado), pp. 100-133.

Clérico, Laura (2007b): “El derecho a la alimentación de los niños, la presunción de exclusión y la necesidad de cambiar el estándar de control de las obligaciones estatales iusfundamentlaes. 'Rodríguez', 'Comunidad toba del Chaco' y la sombra de Ramos”, en Jurisprudencia Argentina (Vol. IV, No 6), pp. 1-34.

Clérico, Laura (2008): "Las otras caras de los derechos sociales: las obligaciones iusfundamentales y la desigualdad estructural", en A.A.V.V La Corte y los derechos 2005/2007 (Buenos Aires, SXXI/ADC), pp. 478-494. 
Clérico, Laura (2009a): El examen de proporcionalidad (Buenos Aires, EUDEBA).

Clérico, Laura (2009b): "El derecho de las personas con discapacidad a las prestaciones de una obra social además como un derecho de organización y procedimiento: 'S.M.F' confirma la regla de 'Martín' y 'Gallardo'”, en Jurisprudencia Argentina.

Clérico, Laura (2010): "El matrimonio igualitario y los principios constitucionales estructurantes de igualdad y/o autonomía”, en Clérico/Aldao (coords.), Matrimonio igualitario. Perspectivas sociológicas, politicas y jurídicas (Buenos Aires, EUDEBA).

Contesse, Jorge: "Indigenous Peoples in Chile: The Quest to Become a Constitutional Entity" ponencia presentada en el Simposio Humboldt "Internacionalización del Derecho Constitucional - Constitucionalización del Derecho Internacional", del 4 al 6 de octubre de 2010, Facultad de Derecho (UBA).

De Sousa Santos, Boaventura (2009): Sociología jurídica crítica (Madrid, Trotta).

DulitzKY, Ariel (2007): "El principio de igualdad y no discriminación. Claroscuros de la jurisprudencia interamericana", en Anuario de Derechos Humanos (No 3), pp.15-32.

FernáNdeZ Valle, Mariano (2010): "Después del matrimonio igualitario", en Clérico/Aldao (coords.), Matrimonio igualitario. Perspectivas sociológicas, políticas y jurídicas (Buenos Aires, EUDEBA).

Fraser, Nancy (1990): "Rethinking the Public Sphere: A Contribution to the Critique of Actually Existing Democracy", en Social Text (No 25/26).

Fraser, Nancy (1997): Iustitia Interrupta (Bogotá, Siglo de Hombres Editores/ Universidad de los Andes).

FraSER, Nancy (2006): "Justicia social en la era política de la identidad", en FraSER, N., y HONNETH, A. ¿Redistribución o reconocimiento?: Un debate politicofilosófico (Madrid, Morata).

GaraY, Alberto F. (1989): "Derechos civiles de los extranjeros y presunción de inconstitucionalidad de las normas", en La Ley (Vol. B), pp. 931.

Gargarella, Roberto (2007): "Cómo no debería pensarse el derecho a la igualdad. Un análisis de las opiniones disidentes en el fallo 'Reyes Aguilera”, en Jurisprudencia Argentina (Vol. IV), pp. 67-74.

Gargarella, Roberto (2010): "Matrimonio y diversidad sexual el peso del argumento igualitario", en Clérico, Laura, y AldaO, Martín (coords.), Matrimonio igualitario. Perspectivas sociológicas, politicas y jurídicas (Buenos Aires, EUDEBA). 
Gialdino, R. (2006): "El rescate de la diferencia. Las comunidades indígenas en la jurisprudencia de la Corte Interamericana de Derechos Humanos", en Jurisprudencia Argentina (Vol. III), p. 1178.

HABERMAS, Jürgen (2004): Historia y crítica de la opinión pública (Barcelona, Gustavo Gilli).

Habermas, Jürgen (2005): Facticidad y Validez (Barcelona, Trotta).

HunT, Paul (2005): Relator Especial sobre el derecho de toda persona al disfrute del más alto nivel posible de salud física y mental, misión al Perú.

Kemelmajer de Carlucci, Aida, y Herrera, Marisa (2010): "El principio de no discriminación en una reciente sentencia del Tribunal Europeo de Derechos Humanos. Una cuestión en movimiento desde el ámbito regional y una responsabilidad desde el ámbito estatal”, en La Ley (6/07/2010).

KingSTON, Patricio (2010): "El proceso en los casos de derechos reales comunitarios de los pueblos indígenas", en Abreut de Begher (coord.), Propiedad Indígena (Buenos Aires, Ed. La Ley), p. 133.

Kothari, Miloon (2006): Documento de Naciones Unidas, E/CN.4/2006/118.

MARQUardt, Stephan (1996): "Internacional Law and indigenous peoples", en Steiner, Henry, y Alston, Philip, Internacional Human Rights in context (Oxford, Clarendon Press).

Maurino, Gustavo (2007): "Pobreza y discriminación: la protección constitucional para los más humildes", en ALEGRE, Marcelo, y GargarelLa, Roberto (comp.), El derecho a la igualdad. Aportes para un constitucionalismo igualitario (Buenos Aires, LexisNexis), pp. 313-343.

MECCIA, Ernesto: "Los peregrinos a la ley. Una tipología sobre discursos de expertos, jueces y legisladores en torno a las demandas LGTB y al matrimonio igualitario”, en Clérico, Laura, y AldaO, Martín (coords.), Matrimonio igualitario. Perspectivas sociológicas, politicas y jurídicas (Buenos Aires, EUDEBA).

NASH Rojas, Claudio (2003): "Protección de los derechos humanos indígenas en el Sistema Interamericano", ponencia presentada en el "Seminario de Derechos Indigenas: Tendencias internacionales y realidad de los pueblos indigenas del norte de Chile", Universidad Arturo Prat, Iquique-Chile, diciembre de 2003.

Parra Vera, Oscar (2008): Protección Internacional de los Derechos Económicos, Sociales y Culturales (San José de Costa Rica, IIDH).

RAMíreZ, Silvina (2008): "Derechos de los pueblos indígenas: protección normativa, reconocimiento constitucional y decisiones judiciales", en: GARGARELLA, R. (coord.), Teoría y Crítica del Derecho Constitucional (Buenos Aires, Abeledo Perrot), Tomo II, p. 921. 
SABA, Roberto (2007): “(Des)Igualdad estructural, en AlEgre, Marcelo, y GaRGARELla, Roberto (comp.), El derecho a la igualdad. Aportes para un constitucionalismo igualitario (Buenos Aires, LexisNexis).

Schujman, Gustavo; Cardinaux, Nancy, y Clérico, Laura (2007): Derechos humanos: conceptos, problemas y desafíos [fecha de consulta 31/12/2010]. Disponible en http://campus.cepa.edu.ar

Stavenhagen, Rodolfo (2010): "Las identidades indígenas en América Latina", en Revista IIDH (No 52), pp. 171-191.

Treacy, Guillermo (2006): "La utilización de categorías sospechosas como técnica para controlar la discriminación hacia los extranjeros", en Jurisprudencia Argentina (2006-IV).

Young, Iris (1989): "Polity and Group Difference: A Critique of the Ideal of Universal Citizenship", en Ethics (Vol. 99, No 2), pp. 250-274.

\section{JURISPRUDENCIA}

Corte IDH:

Caso de la Comunidad Indígena Yakye Axa vs. Paraguay. Fondo, Reparaciones y Costas, Sentencia de 17 de junio de 2005. Serie C No 125.

Caso Comunidad Indígena Sawhoyamaxa vs Paraguay. Fondo, Reparaciones y Costas, Sentencia de 29 de marzo de 2006. Serie C No 146.

Caso Comunidad Mayagna (Sumo) Awas Tingni vs. Nicaragua, Sentencia de 31 de agosto de 2001. Serie C No 79.

Caso Comunidad Moiwana c. Suriname, Sentencia de 15 de junio de 2005. Serie C No 124.

Caso Comunidad Indígena Xákmok Kásek vs. Paraguay, Sentencia del 24 de agosto de 2010. Serie C No 214.

\section{Otros tribunales:}

United States Supreme Court, "Plessy vs. Ferguson”, 163 U.S. 537 (1896).

United States Supreme Court, "Brown vs. Board of Education”, 347 U.S. 483 (1954).

Tribunal Europeo de Derechos Humanos, Casp Schalk y Kopf vs. Austria, sentencia del 24/06/2010.

Fuero Contencioso Administrativo y Tributario, Ciudad Autónoma de Buenos Aires, Freyre Alejandro y otro c/ GCBA s/ Amparo (expte. N 34292/0). 
Fuero Contencioso Administrativo y Tributario, Ciudad Autónoma de Buenos Aires, Canevaro Martín y otro c/ GCBA s/ Amparo (expte. No 36410/0).

Fuero Contencioso Administrativo y Tributario, Ciudad Autónoma de Buenos Aires, Fernández Alberto Daro y otro c/ GCBA s/ Amparo (expte. No 36320). Tribunal Constitucional Alemán, BVerfGE 88, 203 (254, 257, 265, 262).

\section{INFORMES}

Corte IDH. Propuesta de Modificación a la Constitución Politica de Costa Rica Relacionada con la Naturalización. Opinión Consultiva OC-4/84 del 19 de enero de 1984.

Corte IDH. Condición jurídica y derechos humanos del niño. Opinión Consultiva OC-17/02 del 28 de agosto de 2002.

Corte IDH. Condición Jurídica y Derechos de los Migrantes Indocumentados. Opinión Consultiva OC-18/03 del 17 de septiembre de 2003. Serie A No 18.

Comité de Derechos Económicos, Sociales y Culturales, ONU, Observación General No 21, diciembre 21 de 2009, E/C.12/GC/21.

Comisión Interamericana de Derechos Humanos, 17/2/2011, Informe Derechos de los Pueblos Indígenas y Tribales sobre sus Tierras Ancestrales y Recursos Naturales.

\section{Notas Periodísticas}

Página 12, "Narrar el hambre", 13/10/07.

Clarin, "Los indígenas llegan a la Corte por los desmontes", 18/2/2009.

Tiempo Argentino, "En Salta desalojan a los pueblos originarios para buscar petróleo", 14/11/2010.

Tiempo Argentino, "Ya son diez los niños muertos por desnutrición en Salta este año", 7/3/2011. 
